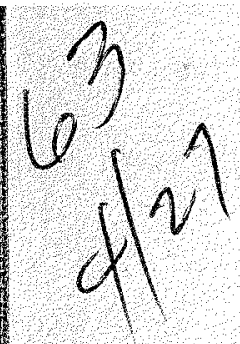

WAPD - TM - 931

AEC RESEARCH AND DEVELOPMENT REPORT

\title{
A STUDY OF PHYSICS PARAMETERS \\ IN SEVERAL WATER-MODERATED \\ LATTICES OF SLIGHTLY ENRICHED \\ AND NATURAL URANIUM
}

MARCH 1970

CONTRACT AT-11-1-GEN-14

BETTIS ATOMIC POWER LABORATORY, PITTSBURGH, PA, OPERATED FOR THE U. S. ATOMIC ENERGY COMMISSION BY WESTINGHOUSE ELECTRIC CORPORATION

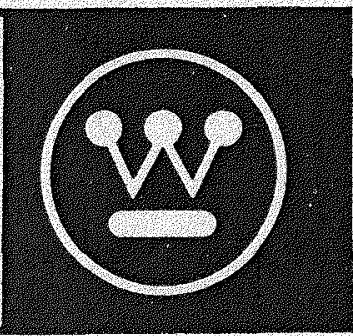




\section{DISCLAIMER}

This report was prepared as an account of work sponsored by an agency of the United States Government. Neither the United States Government nor any agency Thereof, nor any of their employees, makes any warranty, express or implied, or assumes any legal liability or responsibility for the accuracy, completeness, or usefulness of any information, apparatus, product, or process disclosed, or represents that its use would not infringe privately owned rights. Reference herein to any specific commercial product, process, or service by trade name, trademark, manufacturer, or otherwise does not necessarily constitute or imply its endorsement, recommendation, or favoring by the United States Government or any agency thereof. The views and opinions of authors expressed herein do not necessarily state or reflect those of the United States Government or any agency thereof. 


\section{DISCLAIMER}

Portions of this document may be illegible in electronic image products. Images are produced from the best available original document. 
A STUDY OF PHYSICS PARAMETERS IN SEVERAL WATER-MODERATED LATTICES OF SLIGHTLY ENRICHED AND NATURAL URANIUM

J. Hardy, Jr., D. Klein, and J.J. Volpe

March 1970

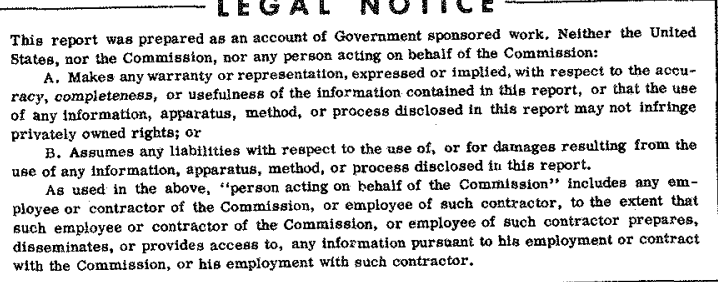

Contract A T-11-1-GEN-14

Printed in the United States of America Available from

Clearinghouse for Federal Scientific and Technical Information National Bureau of Standards, U. S. Department of Commerce

Springfield, Virginia 22151

Price: Printed Copy $\$ 3.00$; Microfiche $\$ 0.65$

This document is an interim memorandum prepared primarily for internal reference and does not represent a final expression of the opinion of Westinghouse. When this memorandum is distributed externally, it is with the express understanding that Westinghouse makes no representation as to completeness, accuracy, or usability of information contained therein.

BETTIS ATOMIC POWER LABORATORY, PITTSBURGH, PA., OPERATED FOR THE U. S. ATOMIC ENERGY COMMISSION BY WESTINGHOUSE ELECTRIC CORPORATION 
No. Copies

AEC Library, Washington for J. M. Simmons

Ames Laboratory (AEC)

Argonne National Laboratory (AEC)

Atomics International (AEC)

Babcock and Wilcox Company (AEC)

Battelle Memorial Institute (AEC)

Battelle-Northwest (AEC)

Brookhaven National Laboratory (AEC)

Combustion Engineering, Inc. ( $A E C$ )

Combustion Engineering, Inc. (NRD) (AEC)

Du Pont Company, Aiken (AEC)

General Electric Company, Cincinnati, (AEC)

General Electric Company, San Jose (AEC)

Gulf General Atomic Incorporated (AEC)

Idaho Nuclear Corporation (AEC)

IIT Research Institute (AEC)

Knolls Atomic Power Laboratory (AEC)

Lawrence Radiation Laboratory, Livermore (AEC)

Los Alamos Scientific Laboratory (AEC)

Mound Laboratory (AEC)

Oak Ridge National Laboratory (AEC)

Westinghouse Electric Corporation (AEC)

DTIE

Manager, PNR

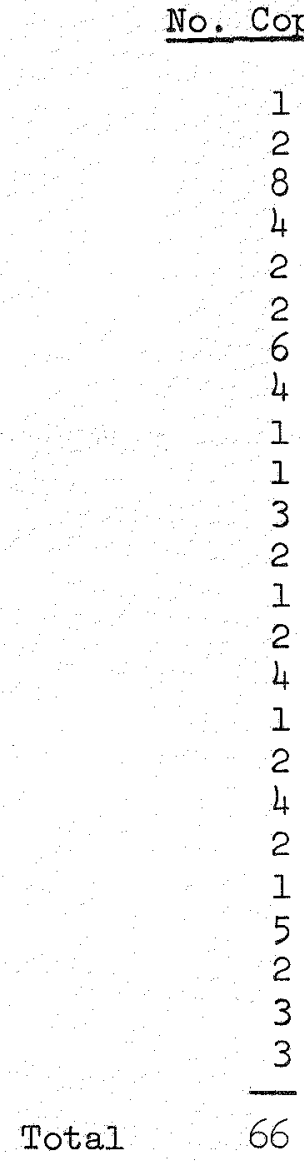

LEGAL NOTICE

This report was prepared as an account of Government sponsored work. Neither the United States, nor the Commission, nor any person acting on behalf of the Commission:

A. Makes any warranty or representation, expressed or implied, with respect to the accuracy, completeness, or usefulness of the information contained in this report, or that the use of any information, apparatus, method, or process disclosed in this report may not infringe privately owned rights; or

B. Assumes any liabilities with respect to the use of, or for damages resulting from the use of any information, apparatus, method, or process disclosed in this report.

As used in the above, "person acting on behalf of the Commission" includes any employe or contractor of the Commission, or employe of such contractor, to the extent that such employe or contractor of the Commission, or employe of such contractor prepares, disseminates, or provides access to, any information pursuant to his employment or contract with the Commission, or his employment with such contractor. 
CONTENTS

Page

I. INTRODUCTION 1

II. MEASUREMENTS 2

A. $U^{238}$ Capture $\left(\rho^{28}\right)$

B. $\mathrm{U}^{235}$ Fission $\left(\delta^{25}\right)$

C. $U^{238}$ Capture/U $\mathrm{U}^{235}$ Fission Ratio $\left(\mathrm{CR}^{*}\right)$

D. $\mathrm{U}^{238} / \mathrm{U}^{235}$ Fission Ratio $\left(\delta^{28}\right)$

E. Fast and Epithermal Spectrum Comparisons 9

III. CALCULATIONAL MODEL 99

A. Lattice Cell Calculation: RECAP . 9

B. Cross Sections 11

1. Uranium-238 11

2. Uranium-235 12

3. Hydrogen 13

4. Oxygen 13

C. Lattice Leakage Corrections: MUFT, MAGMA, P3MG

IV. CALCULATED RESULTS 14

A. Effective Resonance Integrals for $U^{238}$ Rods: RESQ,
ZUT, TUZ

B. Calculated Results for $U^{238}$ Effective Resonance Integrals $\quad 15$

C. Calculated Results for Lattice Reaction Rates 17

V. COMPARISON OF MEASUREMENTSS AND CALCULATIONS

A. Base Calculation versus Experiment 18

1. $\mathrm{U}^{238}$ Capture 18

2. $U^{235}$ Fission 21

3. $\mathrm{U}^{238} / \mathrm{U}^{235}$ Fission Ratio $\left(\delta^{28}\right) \quad 25$

4. Eigenvalues 25

5. Fast and Epithermal Spectrum 26

B. Reduction of $\mathrm{U}^{238}$ Capture $\quad 26$

C. Variation of the $U^{235}$ Epithermal Fission Cross Sections 26

D. Variation of the $U^{238}$ Inelastic Scattering Cross Section 27 


\section{FIGURES}

Figure

$1 \quad$ Typical $U^{238}$ Foil Loadings in TRX (Upper) and Natural Slab (Lower) Lattices

$2 \quad$ Measured Epicadmium and Subcadmium $U^{238}$ Capture Activation Shapes in Natural Slab Lattices with $\mathrm{W} / \mathrm{U}=1.09$ and 0.5 , Normalized to 1.00 at Slab Center (Depth $=500 \mathrm{mils}$ )

Equivalence between CaIculated Resonance Integrals for Isolated Uranium and $\mathrm{UO}_{2}$ Rods

Equivalence between Calculated Resonance Integrals for Isolated Uranium Rods and Rods in Lattices

Comparison of Measured and Calculated Resonance Integrals

for Isolated Uranium Metal Rods

6 Comparison of Measured and Calculated Resonance Integrals for Isolated $\mathrm{UO}_{2}$ Rods

Ratio of Calculation/Experiment versus Experimental $\delta^{25}$

for the TRX and Slab Lattices

Ratio of Calculation/Experiment versus Experimental $\delta^{28}$ for the TRX and Slab Lattices

Calculated Eigenvalues versus Spectrum Hardness Index $\left(\delta^{28}\right)$ for the TRX and Slab Lattices

B-1 Epicadmium Capture-PIus-Fission Activity Relative to Activity of Foil with Capture Only, TRX $\mathrm{W} / \mathrm{U}=8.1 / 1$ 
$1 \quad$ Experimental $\rho^{28}$ Results 30

2 Experimental CR* Results 30

3 Summary of Intra-Cell Structure Measurements for TRX and Slab Lattices

Contributions to the Dilute $\mathrm{U}^{238}$ Resonance Integral

Effective Resonance Integrals for Isolated Uranium and $\mathrm{UO}_{2}$ Rods Calculated by RESQ-ZUT-TUZ

Effective Resonance Integrals in Uranium Metal Lattices Calculated by RESQ-ZUT-TUZ and by RECAP

RECAP Results and Leakage Correction Factors for TRX Lattices

RECAP Results and Leakage Correction Factors for Natural

Slab Lattices

Comparison of Calculated $U^{238}$ Fission Rates and Fast

Advantage Factors

Comparison of Calculated and Measured $\rho^{28}(0.625 \mathrm{ev})$

Comparison of Calculated and Measured $\delta^{25}(0.625 \mathrm{ev})$

Comparison of Calculated and Measured $\delta^{28}$

Calculated Eigenvalues

Comparison of Measured and Calculated Fast/Epithermal Spectrum Results: TRX 1.00/1 Relative to TRX $8.11 / 1$

Comparison of Measured and Calculated Fast/Epithermal Spectrum Results: $0.50 / 1$ and $0.16 / 1$ Slabs Relative to $1.09 / 1$ Slab 
The full-range Monte Carlo program RECAP has been used in a consistent analysis of parameters measured in seven water-moderated uranium lattices: four were TRX lattices of slightly-enriched rods, and three were natural-uranium-slab lattices. The most important parameters were: epithermal-to-thermal ratios for $U^{238}$ capture $(028)$ and for $U^{235}$ fission $\left(\delta^{25}\right)$, ratio of $U^{238}$ fission to $U^{235}$ fission $\left(\delta^{28}\right)$, eigenvalue, integral fast/epithermal spectrum comparisons with a variety of detectors, and resonance integrals for isolated uranium and $\mathrm{UO}_{2}$ rods (calculated with the Monte Carlo program RESQ, supplemented by ZUT and TUZ at higher energies). The analysis of these lattices was fairly unambiguous and has served to test the input nuclear data for $\mathrm{U}^{238}, \mathrm{U}^{235}$, and $\mathrm{H}_{2} \mathrm{O}$. With but one exception, leakage was small (i.e., less than 20 percent), and parameters were measured in nearly asymptotic flux spectra. These measurements covered a wide range of hardness as reflected in the change of parameters: $\rho 28$ ranged from 0.5 to $12 ; \delta 25$ from 0.04 to 1.1 ; and $\delta 28$ from 0.05 to 0.44 . The Monte Carlo cell calculations were corrected for leakage by means of the homogenized lattice programs P3MG and MUFT-MAGMA. With a straightforward choice of current "best" nuclear data, the calculations reproduce virtually all the parameters over the whole range of lattices. There are two qualifications: some reduction of smooth $\mathrm{U}^{238}$ capture integral is required to match the lattice measurements (by an amount barely compatible with the isolated rod measurements), and there is too much calculated epithermal $\mathrm{U}^{235}$ fission in the very tight lattices.

\section{A STUDY OF PHYSICS PARAMETERS IN SEVERAL WATER-MODERATED LATTICES OF SLIGHTLY ENRICHED AND NATURAL URANIUM}

J. Hardy, Jr., D. Klein, and J.J. Volpe

\section{INTRODUCTION}

Several water-moderated lattices of slightly enriched and natural uranium have been analyzed by means of the full-range Monte Carlo program RECAP. The purpose has been mainly to test the cross-section representations for these nuclides, since other approximations in the Monte Carlo program are thought to be adequate. The following measured lattice parameters have been analyzed: ratio of epithermal-to-thermal $U^{238}$ captures $\left(p^{28}\right)$, ratio of epithermal-tothermal $U^{235}$ fissions $\left(\delta^{25}\right)$, ratio of $U^{238}$ captures to $U^{235}$ fissions (CR*), ratio of $U^{238}$ fissions to $U^{235}$ fissions $\left(\delta^{28}\right)$, and multiplication factor $(\lambda)$. In addition, relative spectrum measurements were made with a number of resonance and fast detectors: $\mathrm{Au}^{197}, \mathrm{In}^{115}, \mathrm{U}^{238}$ (capture), $\mathrm{U}^{238}$ (fission), $\mathrm{Al}^{27}(\mathrm{n}, \alpha)$, and $\mathrm{Ni}^{58}(\mathrm{n}, \mathrm{p})$. In some cases, activation shapes were measured and bucklings were inferred where possible. A detailed study of thermal flux spectrum and lattice cell structure is presented in Reference 1 .

There were four TRX metal rod lattices. These consisted of aluminum-clad uranium metal rods 48 inches long, 0.387 inch in diameter; the uranium was 
enriched to 1.3 percent $U^{235}$. The rods were arranged in hexagonal arrays at four water-to-fuel volume ratios: $1.00,2.35,4.02$, and 8.11 . The two intermediate arrays were full lattices for which buckling values were available. The other two arrays were run as inner lattices surrounded by a driver region of TRX high density $\mathrm{UO}_{2}$ rods. At the center, where parameters were measured, the flux spectra were essentially asymptotic. All these lattices were fully reflected, and their perimeters were made as nearly circular as possible.

There were, in adition, three natural slab lattices. These consisted of 24 inch by 24 inch by 1.0 -inch slabs of natural uranium metal arranged in parallel arrays with water-to-fuel volume ratios of $1.09,0.50$, and 0.16 . In each case, there was a highly enriched driver at either end of the natural slab region. These lattices were treated as one-dimensional, with a transverse buckling. In the central region, where parameters were measured, the spectrum was close to asymptotic in the $1.09 / 1$ and $0.50 / 1$ lattices, but this was not true for the tightest slab lattice.

Leakage was relatively small (i.e., in the range of \pm 20 percent) in all cases except the $0.16 / 1$ slab lattice, where it was -80 percent.

A detailed description of the TRX and natural slab cores may be found in Appendix A.

Section II summarizes the lattice parameter measurements. It is intended only to amplify previous descriptions of the activation techniques (References 2 and 3) and to present detailed experimental results. Section III describes the calculations, with primary emphasis on the Monte Carlo portion. Because in most cases the leakage corrections are relatively small, they have been given less emphasis here. Section III also includes a description of the differential cross sections used and a calculation of isolated rod resonance capture integrals for $\mathrm{U}^{238}$. Calculated results appear in section IV. In Section V, the calculated and measured results are compared, parameter by parameter, and conclusions are drawn about the adequacy of the input cross-section data. Some variations of the data are also tried. Finally, section VI summarizes the results and conclusions.

\section{MEASUREMENTS}

A. $\mathrm{U}^{238}$ Capture $\left(\rho^{28}\right)$

The $U^{238}$ capture measurements (References 2 and 3 ) all employed 0.005-inchthick by 0.387 -inch-diameter uranium metal foils, which were depleted to either 
3 or 5 parts-per-milition $U^{235}$. The 100-kev gamma peak activity resulting from decay of $\mathrm{Np}^{239}$ was counted on a 1/4-inch-thick by 2-inch-diameter NaI crystal in a 85- to 120-kev window. Counting started 3 days after irradiation and was continued for several half lives $\left(t_{1 / 2}=2.35\right.$ day $)$.

Figure 1 shows the typical bare and cadmium-covered foil loadings in the TRX lattices. The foils and their depleted uranium shields were carefully machined to give a good fit with the fuel rod. In the cadmium-ratio measurements, the positions of the two loadings were alternated to remove any slight flux asymmetry between them.

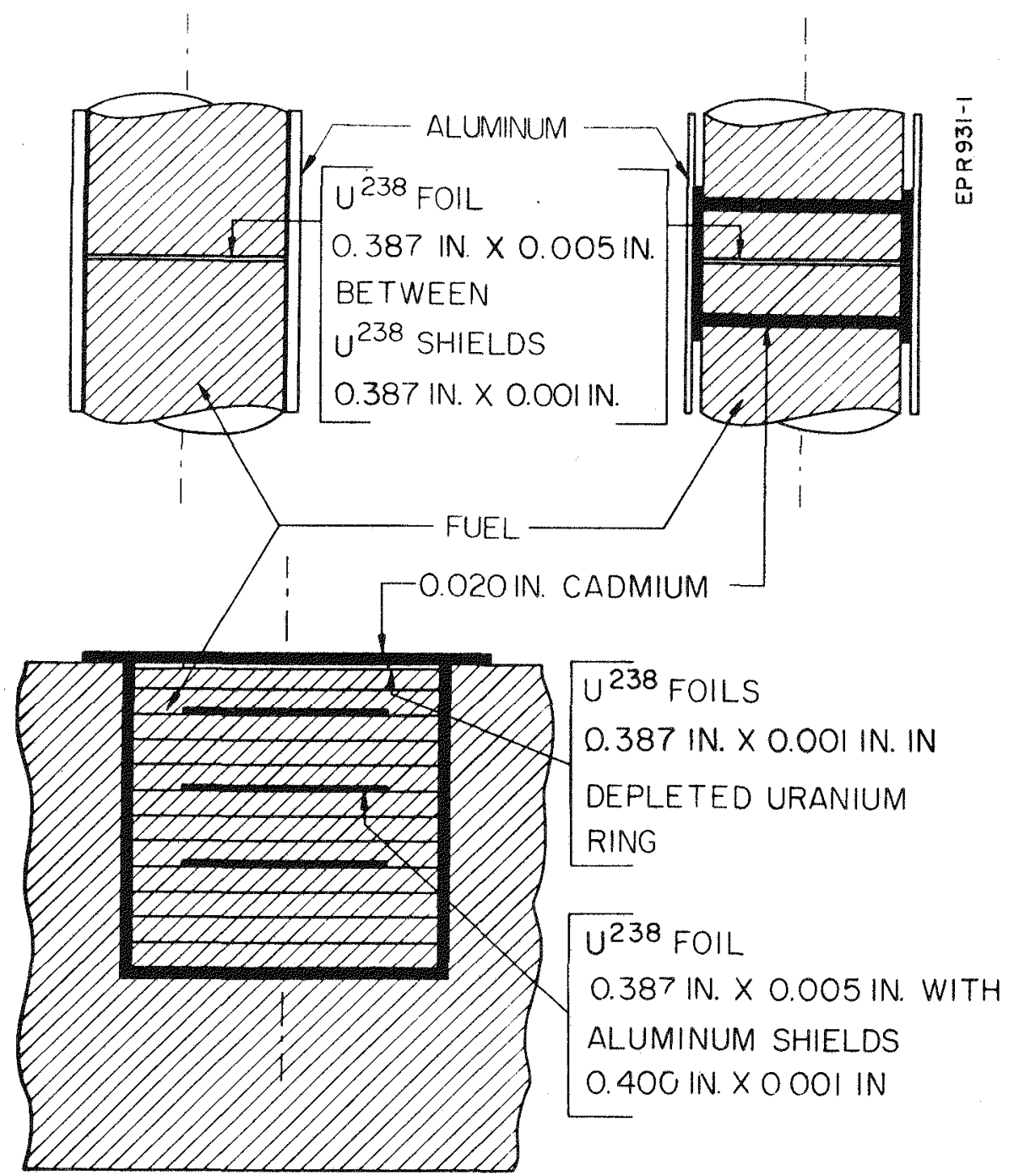

Figure 1. Typical $\mathrm{U}^{238}$ Foil Loadings in TRX (Upper) and Natural Slab (Lower) Lattices. 
There is some $\mathrm{U}^{238}$ fission activity in the $85-$ to $120-\mathrm{kev}$ window, along with the capture activity peak. The importance of this fast-fission background depends directly on the ratio of $\mathrm{U}^{238}$ fission to epithermal $\mathrm{U}^{238}$ capture for each particular lattice. Fast-fission background corrections ranged from 1 to 3 percent, and are discussed in Appendix B. These corrections were obtained mainly from the observed time dependence of the $U^{238}$ foil activity relative to that of a foil with capture activity only. In addition, the corrections were supplemented by some earlier experimental results in which $\mathrm{Np}^{239}$ was separated chemically from the fission products.

In the looser IRX lattices the cadmium box was found to depress the fast flux; hence, it depressed the $U^{238}$ fission activity in a cadmium-covered foil. This implies a slight depression of the very high energy $\mathrm{U}^{238}$ capture. Because the effect was estimated to be small in the worst case ( $<1$ percent in the 8.I/I TRX) and completely negligible in the other cases, a correction for this effect has not been applied. Suppression of the high energy flux by the cadmium box has even less effect on epithermal $U^{235}$ fission and other detectors which activate at relatively low energy.

For thermal neutrons, the $U^{238}$ foil package presented a 0.007 -inch window in the fuel rod. The absorption cross section in this window was substantially reauced by the absence of $U^{235}$. Possible flux perturbation was sought by comparing activation of a $\mathrm{U}^{238}$ foil in the 0.007 -inch window with activation in a 0.017-inch window: however, no effect could be found: the (assumed linear) correction to zero-package thickness amounted to $-0.1 \pm 0.3$ percent.

A further possible systematic error is connected with the counting method. Because epithermal capture activity is strongly peaked around the perimeter, whereas thermal activity is relatively uniform in the TRX foils, the efficiency for counting epithermal activity could be enhanced by reduction of gamma selfabsorption near the edge of the foil. To eliminate this, the foils were in several instances placed in unirradiated rings of $\mathrm{U}^{238}$ during counting. These rings fit tightly around the foils and produced uniform gamma self-absorption for activity at all positions in the irradiated foil. A small effect was observed, amounting to a correction to $\rho^{28}$ of $0.4 \pm 0.2$ percent.

In three of the TRX lattices, $\rho$ was obtained also by the thermal subtraction technique, with both $\mathrm{U}^{235}$ and $\mathrm{Dy}^{164}$ as the reference detectors. This technique is necessary where $\rho^{28}$ is very much greater than unity since one infers the epithermal from the total-minus-thermal capture; in the cadmium-ratio technique, however, one infers the thermal from the total-minus-epithermal capture. This 
method is useful also because it does not involve cadmium-covered $U^{238}$ foils. The cadmium may slightly perturb $U^{238}$ epithermal capture by suppressing the very high energy flux, as previously mentioned, or by the overlap of cadmium and $\mathrm{u}^{238}$ resonances.

The thermal column of the Brookhaven National Laboratory (BNL) graphite research reactor was used to normalize the detectors. In the experiments, simultaneous 1-hour irradiations were performed in the BNL thermal column and in the TRX. The TRX loading consisted of bare Dy-Al, $U^{235}-A l$, and $U^{238}$ foils; the BNL loading consisted of similar foils. The dysprosium-cadmium ratio was measured in the TRX in a separate experiment. From the activations, $\rho^{28}$ is obtained by

$$
\rho^{28}(0.625 \mathrm{ev})=\left[\frac{(\mathrm{TRX} / \mathrm{BNL}) \mathrm{U}^{238}}{\mathrm{Dy}^{164}} \times\left(\frac{\mathrm{CdR}}{\mathrm{CdR}-1}\right)_{\substack{\mathrm{Dy} \\ \text { TRX }}}\right] \times \mathrm{BNIL}-1
$$

where

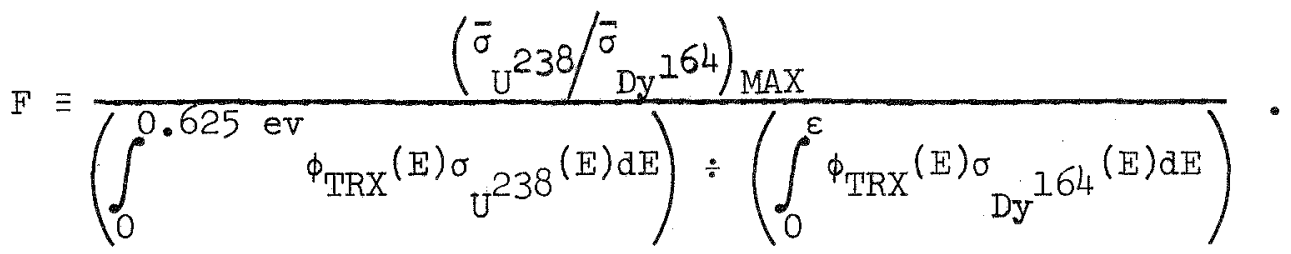

Here,

$$
\begin{aligned}
\text { CdR }= & \text { cadmium ratio } \\
\left(\text { TRX/BNL } \mathrm{U}^{238=}\right. & \text { ratio of } \mathrm{U}^{238} \text { foil activations from the TRX and BNL } \\
\mathrm{F}= & \text { calculated thermal activation ratio reflecting the difference } \\
& \text { in thermal spectrum between the two locations; it is fairly } \\
& \text { close to unity and quite insensitive to the cross sections } \\
& \text { or } \phi_{\text {TRX }}(\mathrm{E}) . \\
\varepsilon= & \text { calculated cadmium cutoff energy for the dysprosium foil } \\
& \text { loading in the TRX. }
\end{aligned}
$$

$\mathrm{U}^{235}$ fission was used as an alternate monitor, with results indistinguishable from those for $\mathrm{Dy}^{164}$. In addition, the bare $\mathrm{U}^{238}$ and $\mathrm{U}^{235}$ activations yielded a direct measurement of the modified conversion ratio (CR*) (Section II.C).

The $\rho^{28}$ results for the TRX lattices are shown in Table 1. There appears to be a slight difference between the cadmium-ratio and thermal-subtraction methods. which could be due to cadmium perturbation of $\mathrm{U}^{238}$ capture. 
In the natural slab lattices, $\rho^{28}$ was measured by a differential technique with the same $U^{238}$ foils. Figure 1 shows the cadmium-covered foil loading. The bare foil loading was similar, with uranium replacing the cadmium in the fuel

slab. Bare and cadmium-covered foil runs were normalized via a monitor foil in the reflector. The $\mathrm{U}^{238}$ epicadmium shape was extended toward the surface with $0.001-i n c h-t h i c k \mathrm{U}^{238}$ foils stacked in the first $5 \mathrm{mils}$. Activation at the surface was obtained with a dilute $\mathrm{U}^{238}-\mathrm{Al}$ foil; shapes were integrated graphically.

Except in the first $50 \mathrm{mils}$, the subcadmium activation was inferred as the difference of the two shapes. To avoid taking the difference of large numbers, a measured subcadmium $\mathrm{Dy}^{164}$ shape was used to extend the $\mathrm{U}^{238}$ thermel distribution to the surface. A calculated $U^{238}$ thermal activation shape was also used. This extrapolation contributed negligible error to the integrated activation over the fuel slab. Figure 2 shows the epicadmium and subcadmium shapes measured in the $1.09 / 1$ and $0.5 / 1$ slab lattices.

For the $0.16 / 1$ slab, $\rho^{28}$ could only be measured by the thermal subtraction method. Hence, bare and cadmium-covered $\mathrm{U}^{235}$ fission and Dy ${ }^{164}$ capture shapes were measured as well as the bare $U^{238}$ shape; all measurements were made relative to a standard monitor location in the reflector. In separate normalizing runs, the monitor activations were compared with activations of corresponding detectors in the BNL thermal column.

Cadmium cutoff energies were ordinarily obtained with the M0199 program; this program uses a one-dimensional, isotropic-incident-flux, pure-absorption model. The spectrum of the incident flux was taken from a MARC Monte Carlo calculation (Reference 4 ) for the appropriate region of the cell. This was coupled to the P3MG (Reference 5) flux spectrum from 0.625 to $5 \mathrm{ev}$, above which energy the cadmium was assumed not to perturb the foil activation. The calculation used the detailed activation cross section of the detector and assumed infinite slab geometry, which neglects the slight extra transmission due to the edge of the real cadmium box.

Because the cadmium box height was significant for $U^{238}$ (Figure 1), cutoff energies were obtained with the SPAN program (References 6 and 7 ), which treated. the two-dimensional pill box geometry explicitly. The calculational model was otherwise the same as in MO199.

For the $0.16 / 1$ slab, where cutoff sensitivity was greatest, the Monte carlo program RECAP of N. R. Candelore and R. C. Gast was used to calculate $U^{235}$ fission activation both bare and cadmium covered. For the latter, the cadmium box 


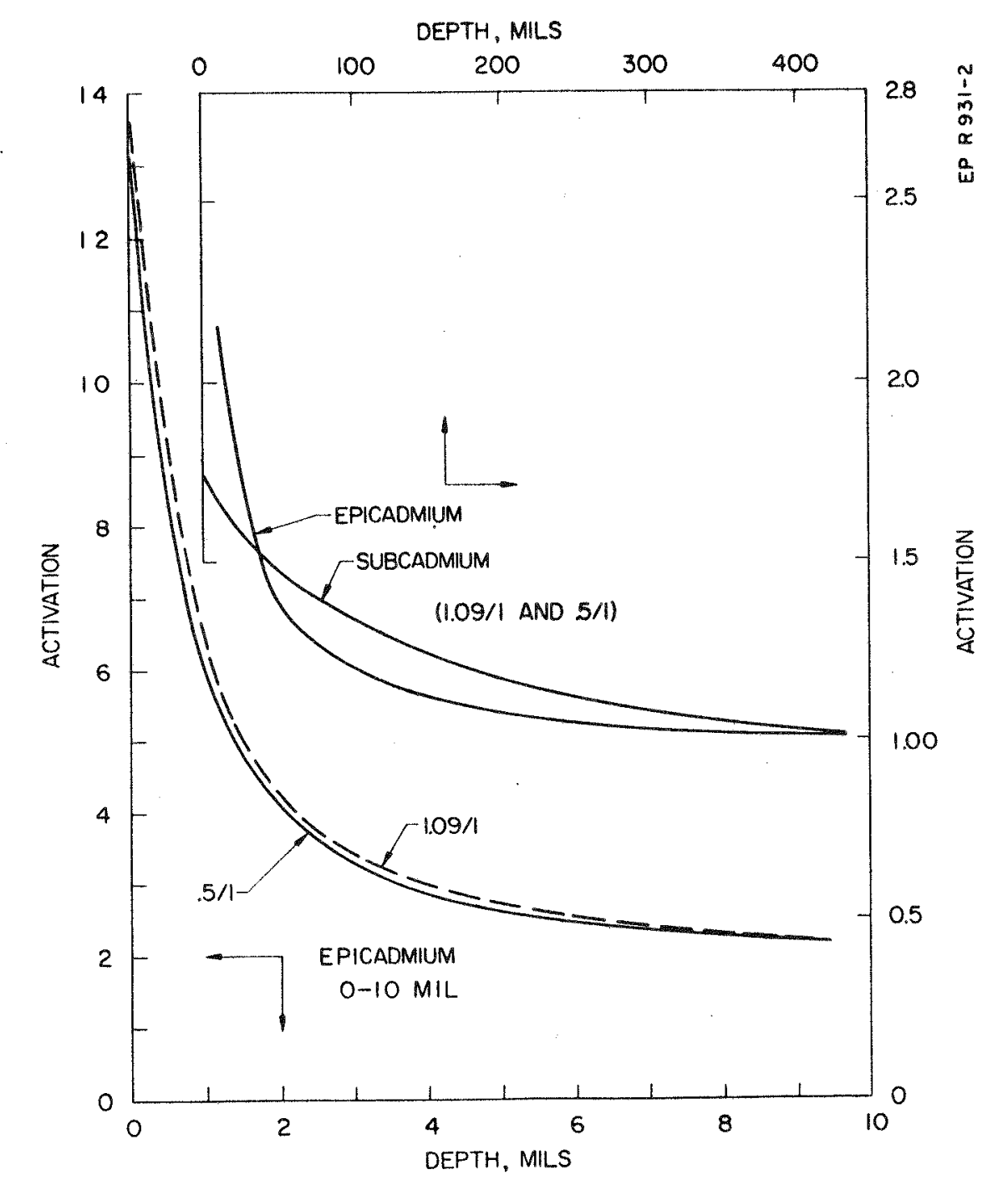

Figure 2. Measured Epicadium and Subcadmium $U^{238}$ Capture Activation Shapes in Natural Slab Lattices with $W / U=1.09$ and 0.5 , Normalized to 1.00 at Slab Center (Depth $=500 \mathrm{mils})$.

(Figure 1) was described explicitly, with the reflecting boundary of the cell at least 0.5 to 0.7 inch away from the cadmium box in all directions. Neutrons were started at $10.7 \mathrm{ev}$ from a slowing down source. Because of the relatively small volume occupied by the box, 80,000 histories were required. There was 1-percent standard deviation on the resulting inferred subcadmium activation of $\mathrm{U}^{235}$, which is used as the reference detector for the thermal subtraction technique [Equations (1) and (2)].

The measured $\rho^{28}$ results for the natural slabs, corrected to a cutoff energy of $0.625 \mathrm{ev}$, are shown in Table 1.

B. $\mathrm{U}^{235}$ Fission $\left(\delta^{25}\right)$

In the TRX, $\delta^{25}$ was measured with 0.005 -inch-thick, 0.387 -inch-diameter $U^{235}-$ Al foils $\left(10 \mathrm{w} / 0 U^{235}\right)$. These were protected from the fuel by 
0.001-inch-thick dysprosium-aluminum foils whose thermal absorption cross section closely matched that of the fuel. Similar integral measurements were made in the slab lattices with rectangular foils. A detailed description of the treatment of $U^{235}$ detectors can be found in Reference 1 . The foil loading for the $\delta^{25}$ measurement was found to cause negligible perturbation of the flux.

In addition, a differential measurement of $\delta^{25}$ was obtained in the $0.16 / 1$ slab in connection with the thermal subtraction method for measuring $\rho^{28}$. In this case, the $\mathrm{U}^{235}$-AI foils from the TRX experiments were positioned across the fuel slab in a manner similar to that shown in Figure 1 . They were shielded against fission product contamination from the fuel by 0.001 -inch-thick aluminum. Activation calibrations were used. The fission $\gamma$ activities were counted with a 2 inch by 2 inch NaI crystal above a bias of $400 \mathrm{kev}$.

The $\delta^{25}$ results are summarized in Table 11 . For the integral $\delta^{25}$ measurements, the cadmium cutoff was calculated with M0199 under the assumption of infinite slab geometry. This is adequate in all cases except perhaps in the tightest natural slab. The differential value of $\delta^{25}$, with a cutoff obtained via RECAP, and the integral result differ by approximately 3 percent.

\section{C. $\mathrm{U}^{238}$ Capture/U $\mathrm{U}^{235}$ Fission Ratio (CR*)}

A second by-product of the thermal subtraction technique for $p^{28}$ was a direct measurement of the modified conversion ratio $\mathrm{CR}^{*}$. This is obtained from the lattice and thermal column activations of $U^{238}$ and $U^{235}$ foils:

$$
\mathrm{CR}^{*}=\left[\frac{(\mathrm{TRX} / \mathrm{BNL})}{(\mathrm{TRX} / \mathrm{BNL}) \mathrm{U}^{238}} \mathrm{U}^{235}\right] \times\left(\frac{\mathrm{U}^{238}}{\mathrm{U}^{235}}\right) \times\left(\frac{\mathrm{U}^{238}}{\bar{\sigma} \mathrm{U}^{235}}\right)_{\mathrm{MAX}}
$$

The $\mathrm{CR}^{*}$ result is less sensitive to cross sections than are the parameters $\rho^{28}$ and $\delta^{25}$. In fact,

$$
\mathrm{CR}^{*}=\left[\frac{\int_{0}^{0.625} \phi_{\mathrm{TRX}}(\mathrm{E}) \sigma_{\mathrm{U}^{238}}{ }^{(\mathrm{E}) d \mathrm{E}}}{\int_{0}^{0.625} \phi_{\mathrm{TRX}}(\mathrm{E}) \sigma \mathrm{U}_{235}(\mathrm{E}) \mathrm{dE}}\right] \times\left[\frac{1+\rho^{28}(0.625 \mathrm{ev})}{1+\delta^{25}(0.625 \mathrm{eV})}\right] \text {. }
$$

The calculated thermal activations in the lattice are essentially the same as those of the thermal subtraction technique. Any calculation which reproduces $\rho^{28}$ and $\delta^{25}$ almost certainly can handle $\mathrm{CR}^{*}$ as well. Direct measurements of $\mathrm{CR}^{*}$ and values inferred from $\rho^{28}$ and $\delta^{25}$ are presented in Table 2 . 
D. $\mathrm{U}^{238} / \mathrm{U}^{235}$ Fission Ratio $\left(\delta^{28}\right)$

A detailed description of the $\delta^{28}$ method appears in Reference 2. A depleted uranium and 1.3 percent enriched uranium foil are irradiated together in the fuel and their fission product gamma activities are counted with a NaI crystal above a bias of $1.2 \mathrm{Mev}$. To relate the observed fission product activities to the corresponding fissions, a secondary experiment is performed with a dual fission chamber. A $U^{238}-U^{235}$ foil pair is irradiated in close proximity to, and hence in the same flux as, a $U^{235}$ deposit and a $U^{238}$ deposit which are in the adjacent chambers of the fission counter. During irradiation, the fissions in each deposit are counted. The fission product activities of the two foils are subsequently counted permitting the evaluation of $\delta^{28}$. The results for $\delta^{28}$ are presented in Table 12.

\section{E. Est and Epithermal Spectrum Comparisons}

Spectrum comparisons were made between the $8.1 / 1$ and $1.0 / 1$ TRX lattices and also among the three slab lattices. The technique involved the use of a reference monitor location where the spectrum was nearly independent of the particular lattice under study. In the TRX lattices, this monitor was in the center of the annular driver region. For the slab lattices, the monitor was adjacent to the highly enriched driver region. P3MG calculations were used in all cases to correct for slight spectrum changes at the monitor location, but such corrections were never more than 2 percent, and usually negligible. Measurements were made in all cases for the $U^{238}(n, \gamma), A u^{197}(n, \gamma), \operatorname{In}^{115}(n, \gamma)$, $\mathrm{U}^{238}(\mathrm{n}, \mathrm{f}), \mathrm{Al}^{27}(\mathrm{n}, \alpha)$, and $\mathrm{Ni}^{58}(\mathrm{n}, \mathrm{p})$ reactions, usually both in the moderator and in the fuel. Tables 14 and 15 show the results of the spectrum comparisons. Table 3 shows the lattice intra-cell structure results obtained with the same detectors. The fast advantage factor is the average activation per atom of a fast detector in the fuel to that of a similar detector in the moderator. The resonance disadvantage factor is the average epicadmium activation per atom of a resonance detector in the moderator to that of a similar detector in the fuel.

III. CALCULATIONAL MODEL

\section{A. Lattice Cell Calculation: RECAP}

The RECAP Monte Carlo program described the lattice cell geometry explicitly. Neutrons were followed over the full energy range below IO Mev. Above $0.625 \mathrm{ev}$, smooth cross sections, including the inelastic scattering transfer matrix, were described in the 54-group MILC energy structure (Ref- 
erence 8). Resolved resonance profiles were described with 1000 equally spaced energy mesh points in each group. Smooth thermal cross sections were described at 25 energies.

Unresolved S-wave resonances of $\mathrm{U}^{238}$ were described at 1000 mesh energies in each MILC group from 2030 to 24,800 ev. The cross section at each energy mesh point was that due to the nearest resonance, selected at random from the appropriate distributions: the Porter-Thomas distribution for $\Gamma_{n}^{0}\left(\Gamma_{n}^{0}=0.00193 \mathrm{ev}\right), \Gamma_{\gamma}$ assumed constant at $0.0246 \mathrm{ev}$. The nearest resonance was assumed to lie with uniform probability in the interval $\pm \frac{D_{0}}{2}$ of the energy mesh point. An approximate Doppler broadening scheme was used in this energy range.

Neutrons were started uniformly in the fuel with fission spectrum 11 of the MILC library. This spectrum, which was produced by D. R. Harris, has a mean energy approximately $40 \mathrm{kev}$ below that of the Watt spectrum. A total-collision estimator and neutron weights were used so that every collision contributed to all possible absorptions at that point. The weight contributed at a collision to absorption of type- $x$ was the initial weight carried by the neutron multiplied by $\Sigma_{x} / \Sigma_{t}$. The remainder of the neutron was allowed to undergo one type of scattering, selected from the appropriate cross sections, and to continue on its way.

In these calculations there was no recycling of fission neutrons (for example, in MOCA (Reference 9) or in RECAP eigenvalue calculations). The reaction rates calculated by $\mathrm{RECAP}$ represent total reactions in the cell normalized to one neutron born of all fission.

Running times were 5 to 8 minutes/1000 histories on the CDC-6600. There were typically 30,000 histories run for each lattice.

To obtain adequate statistical accuracy for the calculated dilute gold and indium resonance capture (used in the spectrum comparisons), it was necessary to run additional RECAP calculations over the range 13.7 to $0.625 \mathrm{ev}$. In each case, 9 experiments were run of 5000 histories each. These were normalized to the corresponding full range Monte Carlo results via the slowing down rate. Even here, due to the relatively narrow lethargy width of the resonances, it was possible to get adequate statistical accuracy only in the moderator. The indium activation in the water (rather than the fuel) was chosen for normalization for this same reason. 


\section{B. Cross Sections}

1. Uranium-238

In the energy range from 0.625 to $2030 \mathrm{ev}$ there were 96 Doppler-broadened, asymmetric, single-level resonances. Ten of these are "probable P-wave" (Reference 10). Interference between resonance and potential scattering was included. Recommended values of reduced neutron width from BNL-325 (Reference II) were used along with a radiative capture width of $0.0246 \mathrm{ev}$.

Based on the ENDF/B analysis (Reference 12), a negative energy resonance $\left(\Gamma_{n}^{0}=0.7884 \times 10^{-3} \mathrm{ev}, \Gamma_{\gamma}=0.0246 \mathrm{ev}, E_{0}=-15 \mathrm{ev}\right)$ was used to make up the thermal capture cross section of 2.73 barns, to which it contributed 0.35 barn. In the thermal range, smooth cross sections were described at 25 energies. The $U^{238}$ capture cross section included non-l/v components from the negative energy resonance and the tail of the 6.7 -ev resonance.

Between 2030 and 24,800 ev, S-wave capture was described by Dopplerbroadened, unresolved resonances with the following parameters: $\bar{\Gamma}_{n}^{\circ}=1.93 \times 10^{-3} \mathrm{ev}$, $D_{0}=21.2 \mathrm{ev}, \Gamma_{\gamma}=0.0246 \mathrm{ev}$ (Reference 11). These parameters yield a strength function $\bar{\Gamma}_{n}^{0} / D_{0}=0.91 \times 10^{-4}$.

P-wave capture below 24,800 ev was treated as smooth:

$$
\overline{\sigma_{\gamma}^{I}(E)}=2 \pi^{2} \lambda^{2} \sum_{J} \frac{g_{J}}{D_{J}} \frac{\Gamma_{\gamma} \bar{\Gamma}_{n}}{\Gamma_{n}+\Gamma_{\gamma}} F_{J} .
$$

The fluctuation correction factor is

$$
F_{J} \equiv \frac{\overline{\sigma_{\gamma}^{I}\left(\Gamma_{n}\right)}}{\sigma_{\gamma}^{I}\left(\bar{\Gamma}_{n}\right)}
$$

where the averages are over the Porter-Thomas distribution. Values of level spacing were $D_{1}(J=I / 2)=21.2 \mathrm{ev}$ and $D_{1}(J=3 / 2)=10.6 \mathrm{ev}$ (Reference 10$)$; the strength function was assumed independent of $J \cdot \Gamma_{\gamma}$ was taken to be $0.0246 \mathrm{ev}$ for these resonances.

Some uncertainty remains about the $P$-wave strength function (Reference 13) with values quoted from below $1.0 \times 10^{-4}$ to $2.5 \times 10^{-4}$. In the first calculations, a value of $2.0 \times 10^{-4}$ was used. This, along with the calculated S-wave cross section, gave fair agreement with the very scattered smooth capture data in BNL-325 in the region from 10 to $30 \mathrm{kev}$. Since the resolved resonances (except for the ten "probable P-wave" resonances) were considered to be S-wave 
only, the full low energy tail of the P-wave cross section, which contributes a falr portion of the $\mathrm{P}$-wave resonance integral, was included. This produced 1.95 barms of $\mathrm{P}$-wave capture integral below $24,800 \mathrm{ev}$.

It was immediately apparent that there was too much smooth capture and very high $\rho^{28}$ values resulted. Although the source of the excess smooth capture cannot be identified, it was decided to arbitrarily reduce the $P$-wave smooth capture cross section so as to produce exactly 1.0 barn of capture integral below $24,800 \mathrm{ev}$. This would imply a strength function around $1.0 \times 10^{-4} \mathrm{which}$, although low, is within the range of quoted values.

From 24,800 ev to $10 \mathrm{Mev}$, the smooth $\mathrm{U}^{238}$ capture cross section followed the curve in BNL-325. Table 4 shows the contributions of each of these sources to the dilute capture integral.

Cross sections for elastic and inelastic scattering were taken from the ENDF/B set (Reference 12) for $U^{238}$ and are based on schmidt's evaluation (Reference 14). The elastic scattering angular distributions were treated as $B_{1}$. There were 21 inelastic levels observed by Barnard, et al (Reference 15) below $2 \mathrm{Mev.} \mathrm{Above} \mathrm{this} \mathrm{energy,} \mathrm{an} \mathrm{evaporation} \mathrm{model} \mathrm{was} \mathrm{used} \mathrm{with} \mathrm{a} \mathrm{temperature}$ obtained from the measurements of Batchelor, et al (Reference 16$)$. The (n,2n) reaction was included in the inelastic scattering energy transfer matrix. Multigroup cross sections were averaged over a fission spectrum. The $\mathrm{U}^{238}$ fission cross section was essentially that of ENDF/B.

2. Uranium-235

The $U^{235}$ cross sections were based on MILC deck 818 above 0.625 ev and on deck 34 of the Bettis thermal library. There were 42 symmetric, single-level resolved resonances up to $40 \mathrm{ev}$, Smooth fission was added to produce a total fission integral of 258.6 barns above $0.625 \mathrm{ev}$. Low energy smooth capture was deleted to produce $\alpha^{-25}=0.55$ above $0.625 \mathrm{ev}$.

The thermal cross sections differed somewhat from the ENDF/B set in the treatment of capture. The $2200 \mathrm{~m} / \mathrm{sec}$ value of $\alpha=0.1700$ (whereas the ENDF/B choice is 0.1734 ). In adition, the deck 34 alpha shows a dip to 0.158 near 0.08 ev before rising in the resonance, whereas the ENDF/B alpha does not. As a consequence, the ENDF/B cross sections would produce eigenvalues somewhat smaller than obtained here (by slightly less than 0.5 percent depending on the case).

Alternate RECAP calculations were done with epithermal $\mathrm{U}^{235}$ cross sections based on the ENDF/B set (the corresponding MILC deck is 718B). There were 87 
resolved, asymmetric single-level resonances up to $61 \mathrm{ev}$, with smooth cross sections above that. In the resolved resonance range, the smooth fission cross section of this deck was adjusted to produce the proper total amount of fission in each group; a similar procedure was used for the capture. In either case, negative smooth cross sections frequently resulted. The resonance integrals above 0.625 ev were 136 barns for capture and 258 barns for fission, with $\alpha=0.527$.

\section{Hydrogen}

The hydrogen cross section corresponds to MILC deck 701. The significant binding effects in water above $0.625 \mathrm{ev}$ were accounted for in deck 701 by adjustment of the slowing-down power in such a way that the flux spectrum in an infinite medium of pure water matched that predicted by the Corngold expansion (Reference 17). For plain water the first moment, the effective temperature, is dominant. Moments were obtained from the Nelkin kernel, for which $T_{\text {eff }}=0.117 \mathrm{ev}$. The RECAP treatment of binding effects above $0.625 \mathrm{ev}$ made direct use of effective temperature approximation in the Corngold expansion: between 0.625 - and $10.7 \mathrm{ev}$, neutron exit energies after collisions with hydrogen were chosen on the assumption that the hydrogen was a free gas at a temperature of $0.117 \mathrm{ev.} \mathrm{Otherwise} \mathrm{the} \mathrm{actual} \mathrm{temperature} \mathrm{was} \mathrm{used.} \mathrm{There} \mathrm{was} \mathrm{no} \mathrm{explicit}$ upscattering above $0.625 \mathrm{ev}$. The hydrogen thermal scattering kernel was a P3 Haywood kernel at a temperature of $296 \mathrm{~K}$. The H-capture cross section at 0.0253 ev was 0.332 barn.

\section{Oxygen}

A RECAP cross-section set was constructed corresponding to MILC deck 402. The thermal scattering kernel for oxygen was a (PI) free gas of mass 16 at a temperature of $296 \mathrm{~K}$.

\section{Lattice Leakage Corrections: MUFT, MAGMA, P3MG}

Leakage corrections for the two full lattices were obtained with the MUFT (Reference 18) program epithermally and from MAGMA (Reference 19) at thermal energies. These programs treated a homogenized, simply-buckled lattice. An "L-factor" was used to force the $\mathrm{U}^{238}$ capture in the zero-buckling MUFT calculation to match that of RECAP between $15 \mathrm{kev}$ and $0.625 \mathrm{ev}$. A single I-factor was applied to $\mathrm{U}^{235}$ absorption (fission plus capture) in a similar manner. Cross sections used in these calculations closely matched those of the Monte Carlo. The BI approximation was used in MUFT; MAGMA performed a P3 or DPI calculation in 36 energy groups. A thermal disadvantage factor was used to force the zero- 
buckling $\mathrm{U}^{235}$ fission rate to match that in the RECAP calculation and a fast advantage factor was applied similarly to obtain the proper $\mathrm{U}^{238}$ fission rate.

Leakage corrections were obtained also with the P3MG-1 and P3MG-2 programs (Reference 5). These performed one-dimensional, 54-multigroup calculations in either slab or cylinder geometry. The calculations were P3 epithermally and double-PI thermally. There was one thermal group for the TRX lattices; six thermal groups were used for the natural slabs. Thermal constants for each homogenized core region were obtained from MAGMA.

In all cases, leakage correction factors for the RECAP-calculated reaction rates were obtained as the ratio of reaction rate in the leaking homogenized lattice to that in the homogenized lattice with zero-buckling. This is adequate for most parameters, with the exception of the fast advantage factor which can be significantly affected by leakage and requires a more elaborate correction (Reference 20).

IV. CALCULATED RESULTS

A. Effective Resonance Integrals for $\mathrm{U}^{238}$ Rods: RESQ, ZUT, TUZ

Low energy resonance capture in isolated rods of uranium and $\mathrm{UO}_{2}$ was calculated with the RESQ program (Reference 21). In each case, one calculation was done for the energy interval from 1 to 100 ev and a second from 100 to $200 \mathrm{ev}$. Doppler broadened, asymmetric single-level resonances were described, including interference scattering, at 8000 energies uniformly distributed over each interval. The rod was assumed to be surrounded by water with a constant scattering cross section and no absorption.

RESQ solves the Boltzman equation exactly. The major portion of the solution is analytic, and is equivalent to the narrow resonance approximation. The remainder is an exact correction obtained by Monte Carlo techniques. Running times were 6 minutes per rod on the Philco-2000, with the Monte Carlo portion ranging from 0 to 35 percent of the total RESQ resonance integral; standard deviations of the RESQ results ranged from 0.06 to 0.12 barn. RESQ is particularly suited to situations involving isolated rods or loose lattices and the lower resonance energies where capture tends to predominate over. scattering. It tends to complement RECAP in this respect.

Resonance capture integrals were also calculated with RESQ for the aluminumclad metal rod lattices. For isolated rods, the program used tabulated placzek escape probabilities; for lattices, RESQ performed a preliminary calculation which produced a table of lattice escape probabilities $\mathrm{P}^{*}\left(\Sigma_{t} r\right)$. This table 
was used for the RESQ resonance capture calculation and subsequently for the ZUT calculation.

For resolved S-wave resonances between 200 and $2030 \mathrm{ev}, \mathrm{U}^{238}$ capture resonance integrals were calculated with the M0628 program of E. M. Gelbard (the Bettis version of Nordheim's ZUT). It is based on the isotropic collision probability model of Chernick (Reference 22), but obtains the slowing-in integral for the fuel numerically. The moderator collisions are treated in the narrow-resonance, flat-flux approximation. In the Bettis version, admixed oxygen is treated also in the narrow-resonance approximation, so that the program is restricted to high energies where this is adequate. Doppler-broadened, singlelevel resonances are assumed, with interference scattering included. ZUT used Placzek escape probabilities for isolated rods; lattice escape probabilities were obtained from RESQ.

Between 2030 and 24,800 ev, unresolved S-wave capture was calculated with the M0727 program of E. M. Gelbard (the Bettis version of TUZ). This program computes capture in the narrow-resonance approximation for a collection of Dopplerbroadened resonances with a Porter-Thomas distribution of reduced neutron widths. For lattices, unresolved resonance capture integrals were obtained from the lattice/isolated-rod equivalence, with an effective surface-to-mass ratio $\frac{S}{M}(I-C)$. The Dancoff factor $1-C$ was obtained from the black-rod limit of the $P^{*}$ calculation in RESQ.

B. Calculated Results for $U^{238}$ Effective Resonance Integrals

Tables 5 and 6 present the calculated $\mathrm{U}^{238}$ effective resonance integrals for isolated rods of uranium and $\mathrm{UO}_{2}$, and for the metal rod lattices.

For the largest metal rod, a RESQ calculation between 200 and $330 \mathrm{ev}$ was done to check the ZUT result for this interval. The result was (ZUT/RESQ) = $1.009 \pm 0.009$. A similar comparison for the largest $U_{2}$ rod yielded (ZUT/RESQ) = $1.004 \pm 0.004$. Thus, there appear to be no significant differences between the two programs where they are expected to agree.

Figure 3 shows the equivalence between isolated metal and oxide rods in terms of the parameter

$$
\lambda=\frac{4 \mathrm{~N}}{\mathrm{~A}} k \sigma_{\mathrm{PS}}+\left(\frac{\mathrm{M}^{\text {fue } 1}}{\mathrm{M}^{238}}\right)\left(\frac{\mathrm{S}}{\mathrm{M}^{\text {fue }}}\right), \quad 0 \leq \mathrm{k} \leq 1 .
$$

The best fit is obtained with $k=0.50$. Here, $A=238, N=0.602 \times 10^{24}$, and the admixed moderator potential scattering cross section per absorber atom 


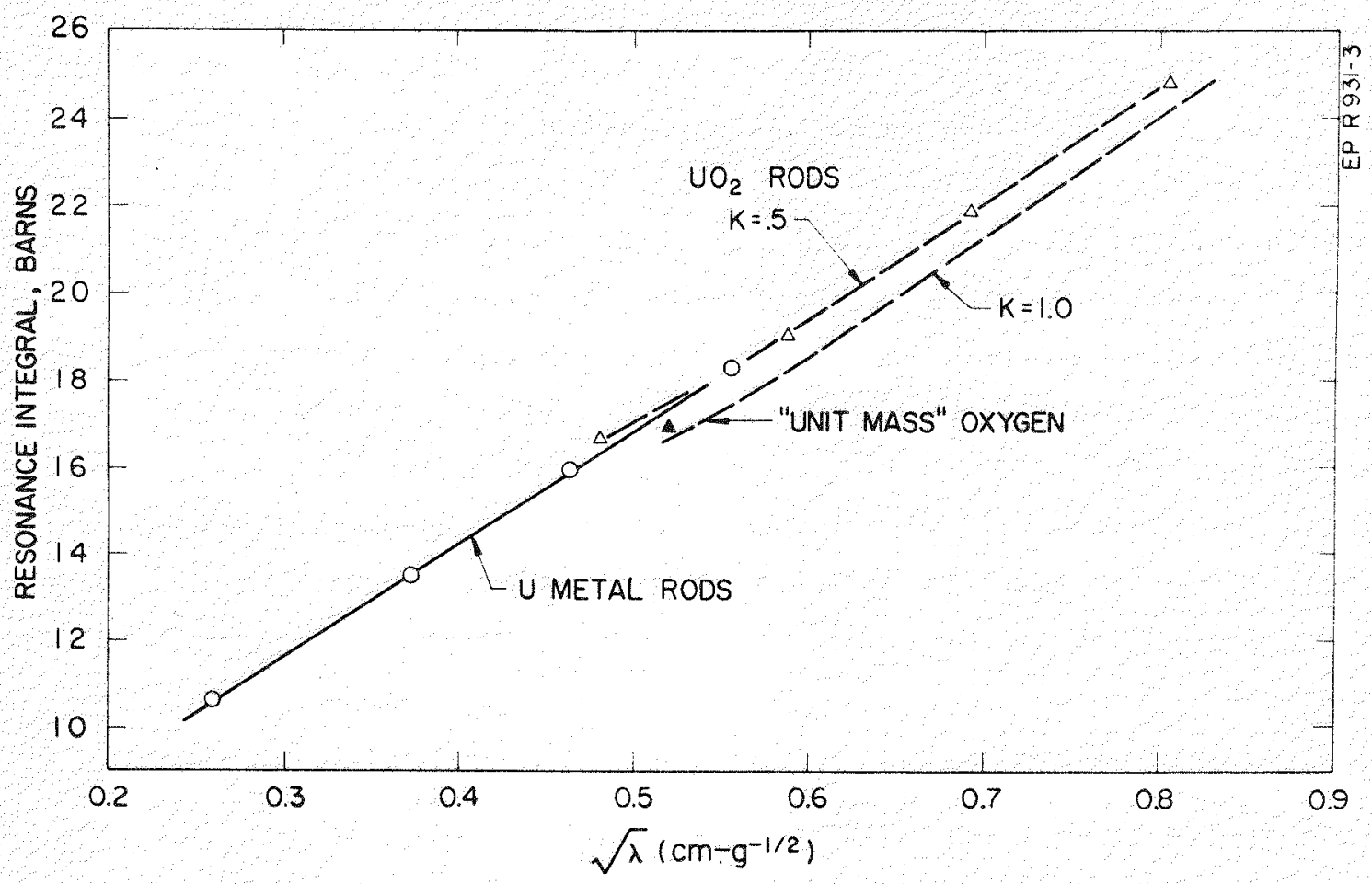

Figure 3. Equivalence between Calculated Resonance Integrals for Isolated Uranium and $\mathrm{UO}_{2}$ Rods.

$\sigma_{\mathrm{PS}}=7.6$ barns. The parameter $\mathrm{k}$ is supposed to account for the fact that the lower energy $U^{238}$ resonances are not narrow with respect to oxygen s lowing down so that the effect of the admixed moderator is reduced. To test this hypothesis, the resonance integral of the largest $\mathrm{UO}_{2}$ rod was recalculated with unit-mass oxygen for which one would expect $k=1$. The effective resonance integral was not increased nearly enough to yield equivalence with $\mathrm{k}=1$ (Figure 3). Thus the equivalence, although valid, is somewhat more empirical than was expected.

Figure 4 shows the lattice/isolated-rod equivalence in terms of the effective surface-to-mass ratio $\frac{\mathrm{S}}{\mathrm{M}}(1-\mathrm{C})$. The exact Dancoff factor is used as well as the rational approximation to it (the Bell approximation, from which the expected equivalence is derived). Only the exact Dancoff factor achieves a satisfactory equivalence between these isolated rods and lattices.

In Table 6 the lattice $U^{238}$ resonance integrals obtained from RECAP show good agreement with those from RESQ-ZUT-TUZ, the RECAP values being about 1.5 percent high. This may be partly statistical and partly due to differences between the models; for example, the way in which resonance integrals are inferred from captures. 


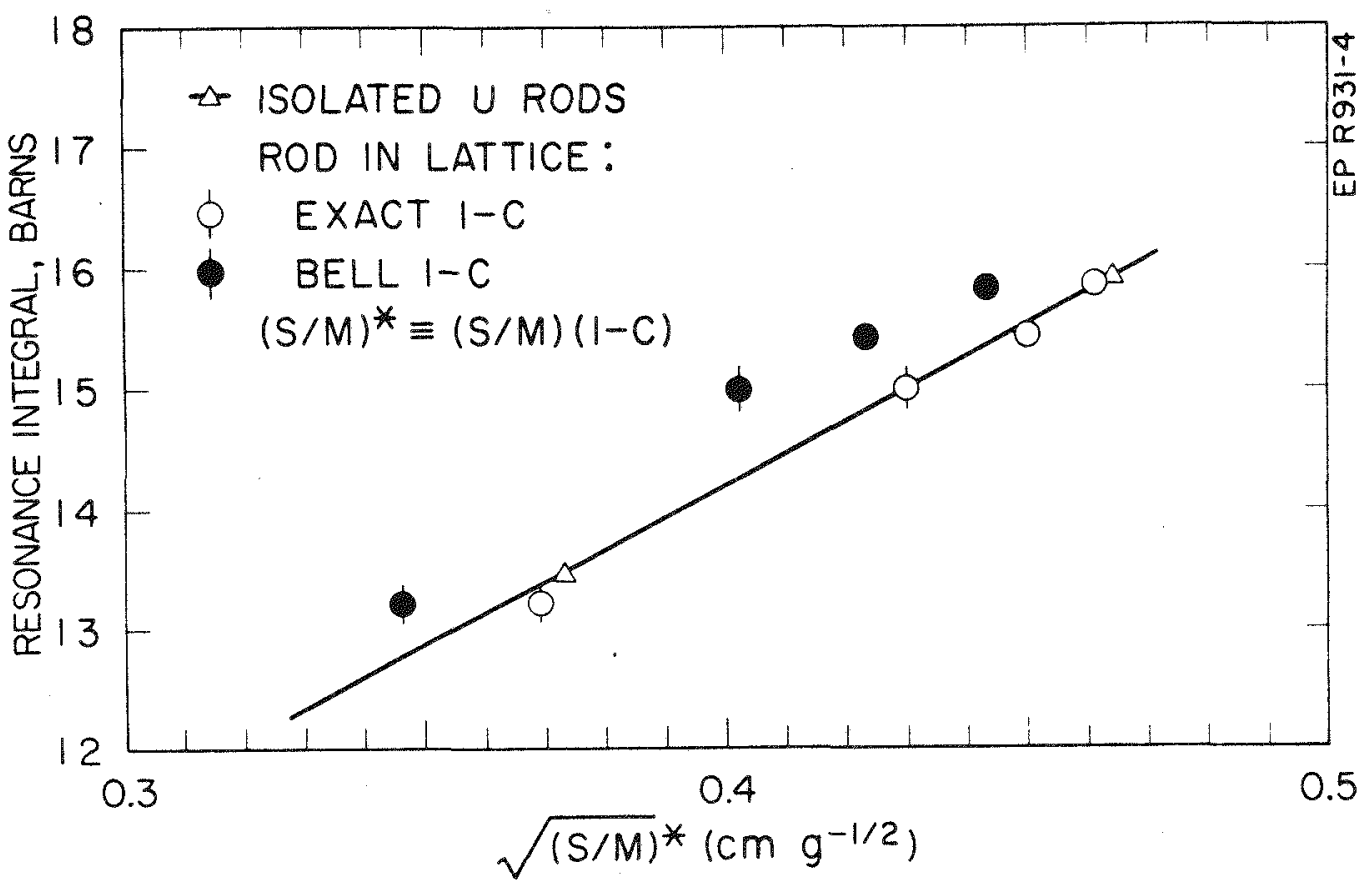

Figure 4. Equivalence between Calculated Resonance Integrals for Isolated Uranium Rods and Rods in Lattices.

\section{Calculated Results for Lattice Reaction Rates}

Tables 7 and 8 show the results of the RECAP calculation of reaction rates in the lattice cells.

$U^{238}$ fission rates and fast advantage factors were previously calculated for these lattices by means of the MOCA2A Monte Carlo program (Reference 20). A comparison of the present RECAP results with those from MOCA is shown in Table 9. The principal difference between the two calculations is in the $U^{238}$ inelastic scattering cross sections which are somewhat larger in RECAP. For these lattices, however, the fast advantage factor is quite insensitive to the fuel cross section (Reference 20). It is reassuring, therefore, that the two programs are in good agreement about the fast advantage factor. As far as the $U^{238}$ fission rate is concerned, only in the tightest lattice does a difference appear, and it is attributed to the difference of $U^{238}$ inelastic cross sections.

\section{COMPARISON OF MEASUREMENTS AND CALCULATIONS}

The measurements are compared first with the base calculation (designated Calculation A). This includes the lattice parameters $\left(\rho^{28}, \delta^{25}, \delta^{28}, \lambda\right)$, isolated rod resonance integrals for $U^{238}$ capture, and the fast/epithermal spectrum comparisons. 
Several modifications of the input data are tried either to improve agreement with experiment or to find the sensitivity of the parameters to the more obvious data variations. Interrelation of the parameters allows quite a bit of adjusting, but it rapidly leads to diminished return for the effort. For this reason, only a limited number of variations are examined. These are:

Calculation $B$ : Reduction of the $U^{238}$ smooth capture integral by 0.35 barn.

Calculation $\mathrm{C}$ : Use of deck $718 \mathrm{~B} \mathrm{U}^{235}$ epithermal cross sections (based on the ENDF/B evaluation) instead of deck 818. RECAP was used so that differences are partly statistical.

Calculation D: Use of YOM64 (Reference 23) inelastic scattering for $\mathrm{U}^{238}$ instead of the ENDF/B cross sections.

These changes are cumulative: each calculation encompasses all previous changes. In adition, the Watt spectrum and a lower $\mathrm{U}^{238}$ fission cross section are tried.

\section{A. Base Calculation versus Experiment}

\section{U U $^{238}$ capture}

The resonance parameters produce a dilute capture integral of 270 barns, with an uncertainty of 4 to 5 percent (Reference 24). The measured value, normalized to a gold resonance integral of 1565 barns is $286 \pm 10$ barns. The calculation is 6 percent low, but within the overall uncertainties.

Figures 5 and 6 show the isolated rod resonance integrals recommended by Hellstrand and also Hellstrand's own results (Reference 24). These resonance integrals also are normalized to $I_{A u}=1565 \pm 40$ barns which is the mean of the 1575 barn-value calculated from resonance parameters and the 1555-barn result measured by Jirlow and Johanns on (Reference 25). The recommended values have an uncertainty of \pm 3.5 percent.

The calculated values obtained from RESQ-ZUT-TUZ are shown as points. An extra 0.45 barn of smooth capture integral has been added to the calculation to achieve the best overall agreement. Except for the largest $\mathrm{UO}_{2}$ rod, agreement is fair with the recommended values and excellent with Hellstrand's own results. The calculated value for the largest $\mathrm{UO}_{2}$ rod shows a departure from the linear dependence on $\sqrt{S / M}$ which is not present in the measurements. A similar result was found for $\mathrm{ThO}_{2}$ (Reference 26); the reason for this behavior is not known. 


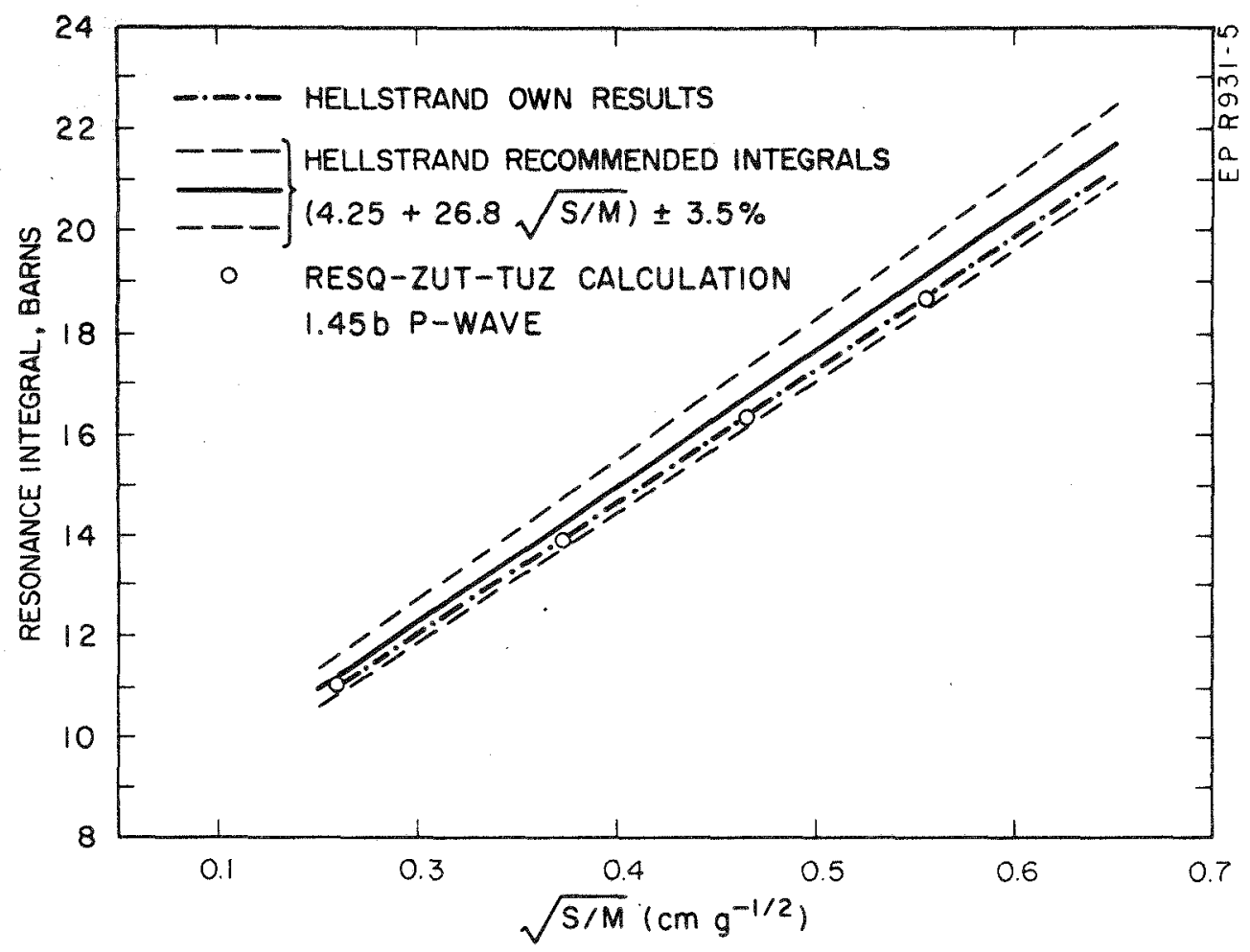

Figure 5. Comparison of Measured and Calculated Resonance Integrals for Isolated Uranium Metal Rods.

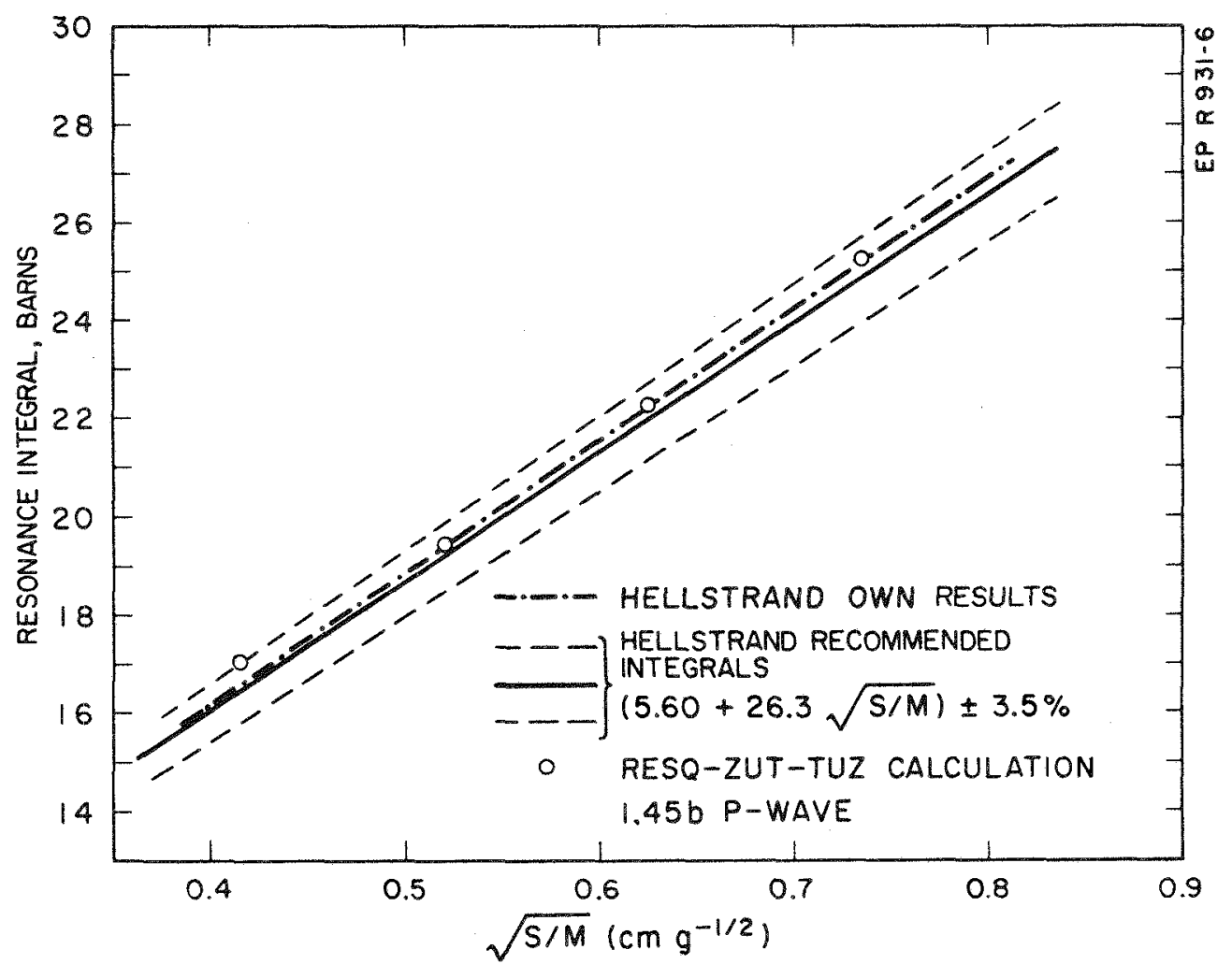

Figure 6. Comparison of Measured and Calculated Resonance Integrals for Isolated $\mathrm{UO}_{2}$ Rods. 
Table 10 and Figure $7(\mathrm{~A})$ compare the measured and calculated results for $\rho^{28}$. The base calculation is consistently high by about 3 percent which implies 0.35 barn excessive smooth capture integral. Thus, altogether these lattice results require 0.80 barn less smooth capture integral than is needed to fit the isolated rod measurements. This amounts to 6 percent on the average. In similar studies, Hellens (Reference 27) observed somewhat less, while Winfrith (References $28,29,30$ ) reports a difference of 10 percent or more.

The 6-percent difference between the lattice and isolated rod results is just at the limit of uncertainty allowed by the two sets of measurements. It is not possible to identify a single source of difficulty. Such things as spectrum corrections, fission product corrections, and the reference value of the gold resonance integral may be significant factors.

As mentioned before, straightforward application of the $\mathrm{U}^{238}$ differential cross-section data suggests that there should be about 2 barns of smooth P-wave capture integral below $25 \mathrm{kev}$, while the present lattice results allow only 0.65 barn of such capture if one assumes the other differential data to

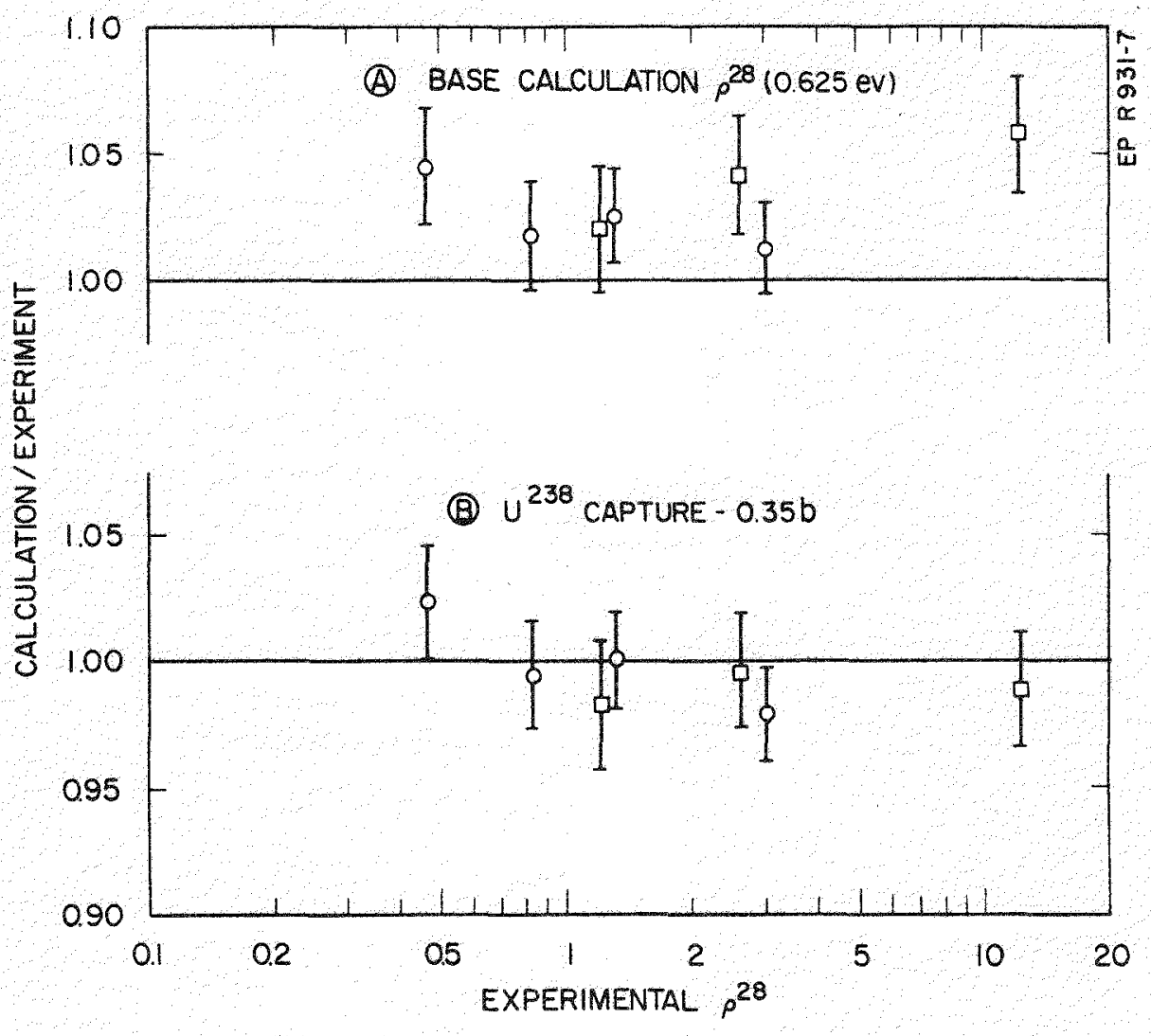

Figure 7. Ratio of Calculation/Experiment versus Experimental $\rho^{28}$ for TRX and Slab Lattices. 
be correct. It cannot, however, be assumed that the difficulty lies entirely at higher energies. There are still enough uncertainties in parameters of resolved resonances to account for this situation. For example, the 0.4915 -centimeter rod resonance integral was recalculated (up to $720 \mathrm{ev}$ ) with resonance parameters reported by Asghar, et al (Reference 31). The result was 0.46 barn higher than with the BNL-325 parameters (Table 5), due almost entirely to the $21.0 \mathrm{-ev}$ level. For this, the Asghar, et al, parameters were (in Mev): $\Gamma_{\gamma}=33.83 \pm 4.3$ and $\Gamma_{n}=9.34 \pm 0.5$; the BNI-325 recommended values were: $\Gamma_{\gamma}=26 \pm 4$ (although 24.6 was used in the calculations) and $\Gamma_{n}=8.5 \pm 0.5$.

New values of $\Gamma_{\gamma}$ from the Petrel test have been reported recently by Glass, et al (Reference 32). In the energy range from 30 to $2050 \mathrm{ev}$, they measured radiation widths for $62 \mathrm{~S}$-wave levels, with an average $\Gamma_{\gamma}=19.1$ ( \pm 0.6 stat, \pm 1.4 sys) Mev. These parameters were used to recalculate the resonance integrals for metal rods (Table 5) with the smooth capture held fixed. The overall result depends very much, however, on the assumptions about $\Gamma_{\gamma}$ for the lowest $U^{238}$ resonances. If one assumes that $\Gamma_{\gamma}$ is as $10 \mathrm{w}$ as $19.1 \mathrm{Mev}$ for the $6.67 \mathrm{ev}$ and $21.0 \mathrm{ev}$ levels also, the metal rod resonance integrals are reduced 9 percent for all rod sizes; the dilute integral is reduced 6 percent. Less drastic changes occur if the radiation widths of the two lowest levels are kept at $24.6 \mathrm{Mev}$. Then metal rod resonance integrals are reduced 4 percent; the dilute integral is reduced 3 percent. In either case, the lower rod resonance integrals could accommodate more high energy smooth capture, which is desirable. Unfortunately, these parameters alter the slope of resonance integral versus $\sqrt{\frac{S}{M}}$ plots and also reduce the dilute resonance integral even further below experiment.

The BNL 325 values for $\Gamma_{\gamma}$ are $26 \pm 2 \mathrm{Mev}$ and $26 \pm 4 \mathrm{Mev}$ for the 6.67 ev and $21.0 \mathrm{ev}$ levels, respectively. If one uses the upper limits $\left(\Gamma_{\gamma}=28\right.$ and $30 \mathrm{Mev}$, respectively) and the Petrel parameters for the other resonances, there is essentially no change in the metal rod resonance integrals.

Glass, et al (Reference 32) also observed 200 presumed P-wave resonances for which $S_{1}=(1.8 \pm 0.3) \times 10^{-4}, D_{I}=7.0 \pm 0.5 \mathrm{ev}$, and $\mathrm{g}_{\mathrm{I}}^{-1}=(3.7 \pm 0.7) \times 10^{-3} \mathrm{ev}$. These values are very close to the ones used originally in these calculations, and with $\Gamma_{\gamma}=19.1 \mathrm{Mev}$, yield 1.75 barn of P-wave integral below $25 \mathrm{kev}$.

\section{U235 Fission}

Table 9 and Figure 8(A) compare the measured and calculated results for $\delta^{25}$. There is a clear departure from agreement in the tighter lattices with the calculation being about 10 percent high in the hardest spectrum. 


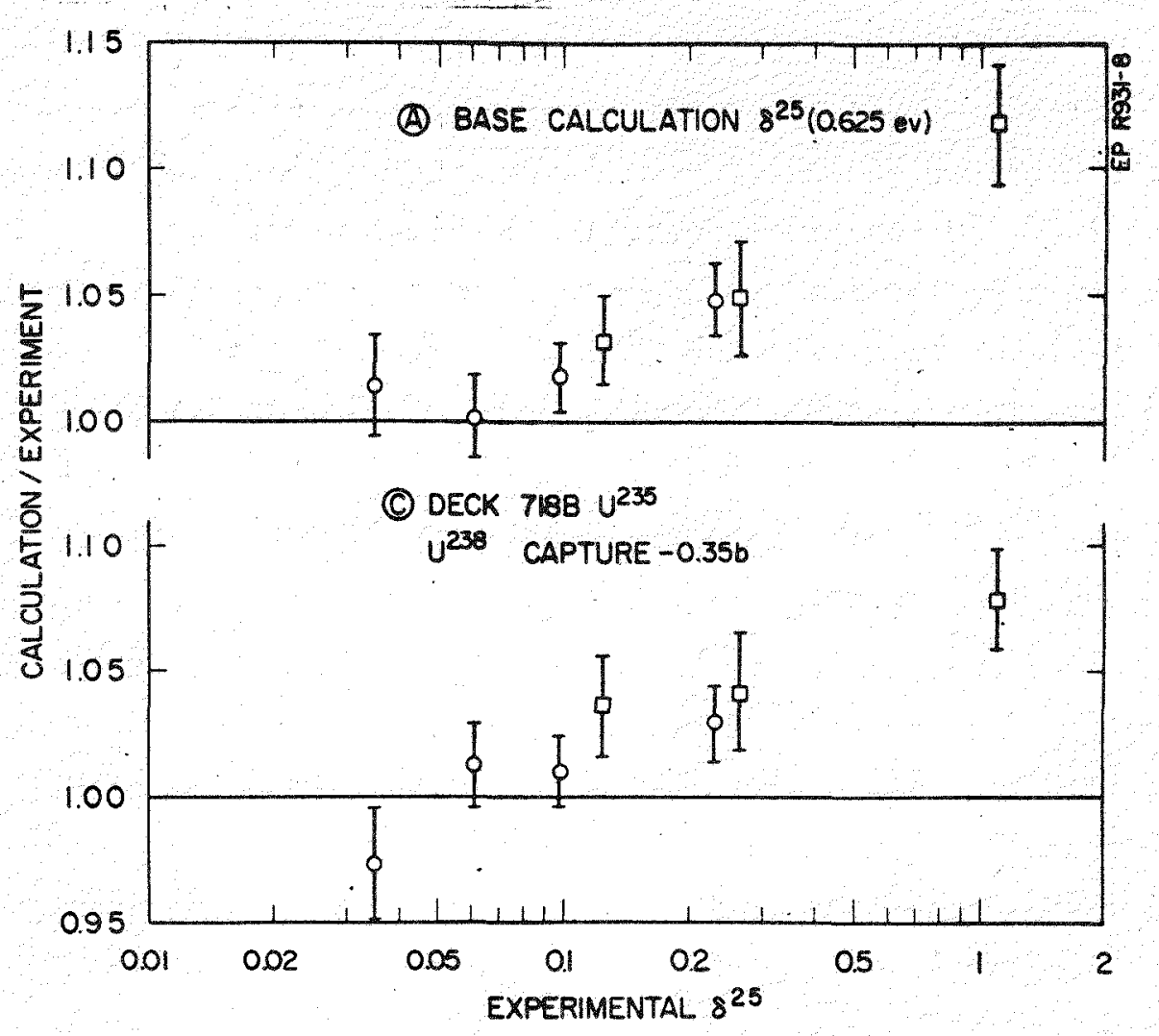

Figure 8. Ratio of Calculation/Experiment versus Experimental 825 for the TRX and Slab Lattices.

The $\delta^{25}$ results were not sensitive to variations of the other nuclear data and, as will be seen, a very similar behavior occurred with deck $718 \mathrm{~B}$ resonance data for $\mathrm{U}^{235}$ in calculation $\mathrm{C}$. It seems unlikely that the thermal fission calculation itself could be a significant source of the trouble. At present, the most likely source of difficulty is the calculated epithermal fission immediately above $0.625 \mathrm{ev}$.

If the $\delta^{25}$ discrepancy is indeed due to an excess of low epithermal $U^{235}$ fission in the calculation, it has little effect on the other parameters. This was checked in the $0.16 / 1$ slab lattice (the extreme case), where $\delta^{25}$ was changed by reducing the $\mathrm{U}^{235} \mathrm{~L}$-factor. It was found that the total amount of $\mathrm{U}^{235}$ fission (including thermal) was essentially unchanged so that $\delta^{28}$ and $\lambda$ were unaffected. The only effect was on $\rho^{28}$ : the percent change of $\rho^{28}$ was in the same direction as that of $\delta^{25}$ and just half as much. Thus, repair of the $\delta^{25}$ trouble would be expected to have a significant effect only in the $0.16 / 1$ slab where $p^{28}$ would decrease by approximately 4 percent. 


\section{3. $\mathrm{U}^{238} / \mathrm{U}^{235}$ Fission Ratio $\left(\delta^{28}\right)$}

Table 12 and Figure $g(A)$ compare the measured and calculated values for $\delta^{28}$. With the ENDF/B inelastic scattering and fission cross sections for $U^{238}$, and fission spectrum 1l, there is good overall agreement.

4. Eigenvalues

Table 13 and Figure 10(A) show the calculated eigenvalues. These are presented as a function of measured $\delta^{28}$ which is a good index of spectrum hardness. For the TRX lattices, results are presented for explicit P3MG calculation of the actual cores. For the two full TRX lattices, where measured buckling values were available, eigenvalues were obtained also with the MUFT-MAGMA programs. These two procedures yielded similar results and, in fact, for the TRX lattices, all the calculated eigenvalues are in good agreement with experiment.

For the slabs, full core calculations were done with the P3MG program. These produced core eigenvalues close to unity, an indication that the highly enriched driver regions (which dominated the neutron economy of the cores) were being handled reasonably well, but the activation shapes into the center were not necessarily consistent with experiment.

In the two loosest slab lattices, there was an asymptotic region in which activation shapes and parameters were measured. The interesting question is: how sensitive is the eigenvalue to leakage in the central portion of the blanket region, and how much variation of eigenvalue is allowed by uncertainty in fitting the measured activation shapes? To answer this question, the core eigenvalue was varied (by varying the size of the driver) so as to produce activation shapes across the central asymptotic region in best agreement with experiment. Due to experimental uncertainties, calculational approximations, the limited size of the blanket region, and the variety of detectors used, a range of eigenvalues was allowed by the measured shapes. The choice of a best fit and range of allowable fit was somewhat subjective since it involved a judgment as to the overall fit of a number of activation shapes. The problem was not serious in the 1.09/1 and $0.5 / 1$ slab lattices where there was an asymptotic region of reasonable size.

This procedure was also used in the tightest lattice where the central region was not asymptotic and where leakage was large. In this case, the shapes were different and steep. Because leakage is so important in this lattice, the eigenvalue is very sensitive to it and hence to one's ability to fit the shapes. Eigenvalue uncertainties stemming from this source are indicated in Table 13 
and Figure 10. The spread of eigenvalues allowed by the measured shapes is comparatively small for the two loosest lattices, but not for the $0.16 / 1$ lattice where leakage is very strong. The other lattice parameters were much less sensitive to leakage uncertainties and only in a few cases was this important.

The eigenvalues in the natural slab lattices are low and appear to decrease in the tighter lattices.

\section{Fast and Epithermal Spectrum}

Table 14 compares the calculated and measured epithermal spectrum results for the $8.11 / 1$ and $1.00 / 1$ TRX lattices. The quantity listed is the ratio of detector activation per atom in the $1.00 / 1$ to that in the $8.11 / 1$, normalized to unity for indium. The gold and indium results (both measured and calculated) refer to the water. This was necessary to obtain decent statistical accuracy in the calculations; the $U^{238}$ rates are in the fuel. Similar results for the $0.500 / 1$ and $0.16 / 1$ slabs (relative to the $1.09 / 1$ slab) are shown in Table 15.

There is good agreement between calculation and experiment except for $\mathrm{U}^{238}$ fission in the $0.5 / 1$ slab lattice. Here the calculation is 7 percent low. The corresponding $\delta^{28}$ calculation (Table 12) is 4 percent low.

These experimental $U^{238}$ fission rate comparisons are not dependent on the fission counter normalization as are the $\delta^{28}$ results. The consistency between these and the $\delta^{28}$ results lends some support to the $\delta^{28}$ measurement technique. B. Reduction of $\mathrm{U}^{238}$ Capture (Table 16)

The homogenized lattice calculations were repeated with 0.35 barn less $\mathrm{U}^{238}$ smooth capture integral (in the kev region). Cross sections were otherwise identical with the original set. The $\rho^{28}$ results are brought into line by this device (Figure $7(B)$ ). Subsequent variations of the data were found to produce negligible changes in $\rho^{28}$.

The $U^{238}$ capture reduction produced an increased amount of $U^{235}$ fission in the tighter lattices and hence a reduction of the calculated $\delta^{28}$ (Figure $9(B)$ ). The ratio of epithermal/thermal $U^{235}$ fission ( $\delta^{25}$ ) was not affected significantly. There was also an increase of eigenvalues, as shown in Figure 10(B), yielding better agreement with experiment.

C. Variation of the $\mathrm{U}^{235}$ Epithermal Fission Cross Sections (Table 17)

The Monte Carlo calculations were repeated with epithermal $\mathrm{U}^{235}$ cross sections corresponding to MILC deck 718B, which is derived from the ENDF/B set. As previously mentioned, this deck also used a single level description, with 
resonances all the way up to $61 \mathrm{ev}$, however. The $\delta^{25}$ results are shown in Figure $8(\mathrm{C})$. There is no qualitative change, but the overall agreement is improved somewhat, especially in the $0.16 / 1$ slab lattice. Some of the differences, for example, for the 8.1/1 TRX, are clearly statistical.

The only other significant effect was a slight reduction of $\lambda$ in the tightest lattices (Figure 10(C)).

It was thought that the relatively crude single-level description of the $U^{235}$ resonances might be a source of difficulty in the heavily shielded situations. To test this hypothesis, RECAP calculations for the slab lattices were repeated with multilevel $U^{235}$ cross sections between 0.625 and 29.0 ev. These cross sections, based on Adler parameters, were furnished by A. Staub and M. Goldsmith, Bettis Atomic Power Laboratory. There was no significant change in the results. D. Variation of the U238 Inelastic Scattering Cross Section (Table 18)

The homogenized lattice calculations were repeated with the YoM64 inelastic cross sections instead of the original ENDF/B set. The two sets differ mainly between 1 and $2 \mathrm{Mev}$. There, the magnitude of the bump in the ENDF/B cross sections seems somewhat suspicious, especially because it occurs just at the transition from resolved levels to the evaporation model.

The YOM64 inelastic cross sections (Reference 23) produced negligible changes of $\rho^{28}$ and $\delta^{25}$. Their effect on $\delta^{28}$ is shown in Figure $9(D)$ where there seems to be a slight improvement of agreement; they led to slightly higher eigenvalues in the slab lattices (Figure $10(D)$ ).

In any case, $\delta^{28}$ and $\lambda$ are also sensitive to the fission spectrum. The harder Watt spectrum* produced $\delta^{28}$ results 3 percent higher in all lattices. It had little effect on other parameters, except for the eigenvalue of the tighter lattices. In the $0.16 / 1$ lattice, the extreme case, $\lambda$ was increased by 0.9 percent.

The distinctly lower $\mathrm{U}^{238}$ fission cross sections chosen by Davey (Reference 33) for fast-reactor calculations produced 8 percent less $U^{238}$ fission in all the lattices. This leads to $\delta^{28}$ values lower by 8 to 9 percent and would yield significantly worse agreement with the measured $\delta^{28}$ values. It would also yield somewhat lower eigenvalues in the tighter lattices. It might be possible to compensate for the lower $U^{238}$ fission cross sections and still maintain reasonable agreement with the present experiments by using a harder fission spectrum and, in the tight lattices, a lower inelastic scattering cross section for $U^{238}$.

* Mean energy $\sim 40 \mathrm{kev}$ greater than that of the Harris spectrum. 
It should be mentioned that the inelastic treatment in previous $U^{238}$ MILC decks (for example, deck 620) (Reference 8), produced distinctly higher $\delta^{28}$ values in the tighter lattices.

\section{SUMMARY AND CONCLUSIONS}

Scraightforward application of current $U^{238}$ differential capture cross-section data, including a P-wave resonance integral of 1.95 barn below $24.8 \mathrm{kev}$, produced too much smooth capture in all the lattices. Although there are enough uncertainties about even the lower energy resonance data to accomodate the differences, the relatively more uncertain $P$-wave smooth capture was adjusted to obtain agreement with experiment.

With only 1.45 barn of $P$-wave capture, the calculated isolated rod resonance integrals show generally good agreement with Hellstrand's recommended values for uranium metal and $\mathrm{UO}_{2}$ rods, and excellent agreement with his own measurements. There is one exception: the calculated value for the largest $\mathrm{UO}_{2}$ rod rises above the linear dependence on $\sqrt{\frac{S}{M}}$, a behavior not shown by the measurements. A similar situation occurred for $\mathrm{ThO}_{2}$ rods and the reason is not understood.

The calculated dilute resonance integral is 6 percent below experiment, just within the assigned uncertainties.

The lattice $p^{28}$ values are quite sensitive to the epithermal $U^{238}$ capture cross sections, particularly in tight lattices, and to very little else. Good agreement has been obtained for all the lattices (with $p^{28}$ ranging from 0.47 to 12). This requires, however, only 0.65 barn of $P$-wave capture, which is 0.80 barn below that needed for the isolated rod measurements. This is about 6 percent on the average, and at the limit allowed by the experimental uncertainties assigned to the respective measurements.

Calculated $\delta^{25}$ values show good agreement with experiment in the loose lattices, but are high in the tight lattices. There is no consistent explanation in terms of thermal absorptions, particularly in light of the thermal spectrum and cell structure studies (Reference 1), so that the difficulty is attributed to epithermal $U^{235}$ fission in heavily shielded situations. This behavior occurred for two cross-section sets (decks 818 and $718 \mathrm{~B}$ ) which differed in detail, but were qualitatively similar; in particular, both had single-level descriptions of the resonances. A multilevel description of the $U^{235}$ cross sections between 0.625 and $29.0 \mathrm{ev}$ did not correct the difficulty. One further possiblity is that 3. refined treatment of molecular binding effects above $0.625 \mathrm{ev}$ might correct the difficulty. 
With the fission spectrum and $U^{238}$ fission cross sections used here (essentially those of ENDF/B), and the ENDF/B inelastic cross sections for $U^{238}$, there is good overall agreement for $\delta^{28}$. There is some indication in the tighter lattices that slightly lower $U^{238}$ inelastic cross sections are necessary, for example, the YoM64 set. The lattice eigenvalues also seem to favor $\mathrm{U}^{238}$ inelastic cross sections slightly below the ENDF/B values.

The direct fast/epithermal spectrum comparisons show generally good agreement with calculation and consistency with the $\delta^{28}$, results, while avoiding the normalization uncertainties connected with the $\delta^{28}$ measurements.

The intracell structure measurements, mainly fast advantage factors for $U^{238}$ fission, show good agreement with experiment and with MOCA calculations.

It would be difficult to accommodate the present $\delta^{28}$ measurements with the approximate 8 percent lower $U^{238}$ fission cross sections recommended by Davey (Reference 33), particularly in the looser lattices where $\delta^{28}$ is insensitive to the $U^{238}$ inelastic cross section. A significantly harder fission spectrum would be required to maintain agreement with our experiments.

In conclusion, the present calculational programs, with a straightforward choice of current "best" cross sections, reproduce virtually all the parameters measured in seven $\mathrm{H}_{2} \mathrm{O}-\mathrm{U}^{238}-\mathrm{U}^{235}$ lattices covering a wide range of spectrum hardness. There are two qualifications: (I) some reduction of the amount of smooth epithermal $U^{238}$ capture integral is required (by an amount barely compatible with isolated rod measurements), and (2) there is too much calculated epithermal $U^{235}$ fission in the very tight lattices where shielding by $U^{238}$ is extreme.

\section{ACKINOWLEDGMENTS}

The authors wish to thank the Bettis CCX and Counting Room staffs for their invaluable support; B. I. Bloch and B. I. Palowitch for the careful experimental and calculational studies of leakage and measurements of $\delta^{28}$ and fast advantage factor in the slab lattices; and I. Itkin for providing some of the $U^{235}$ cross sections. 
TABLE 1. EXPERIMENTAL $p^{28}$ RESULTS

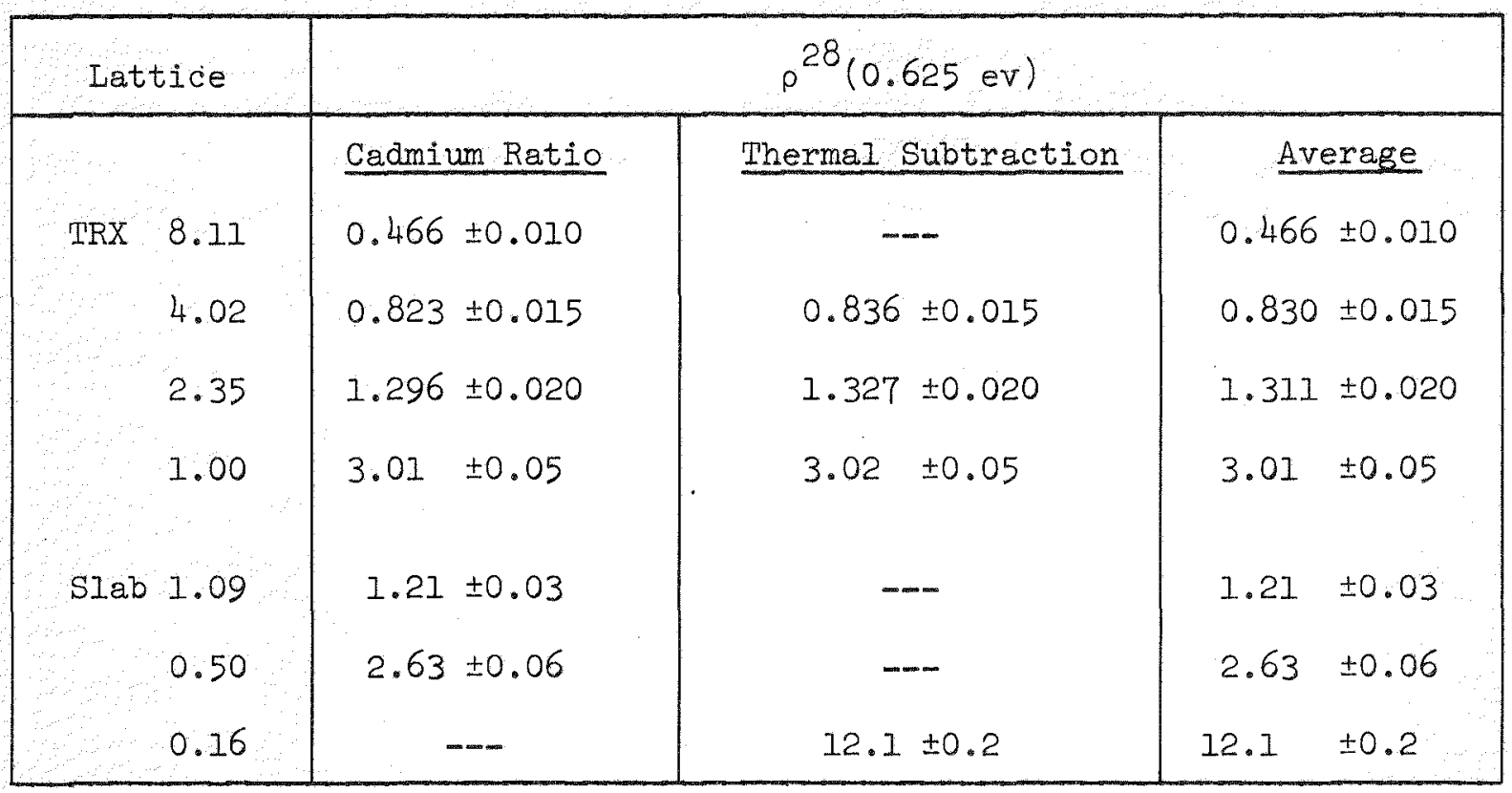

TABLE 2. EXPERIMENTAL CR* RESULTS

\begin{tabular}{|c|c|c|}
\hline Lattice & Direct & From $\rho+\delta^{25}$ \\
\hline TRX 8.11 & $-\cdots$ & $0.526 \pm 0.004$ \\
4.02 & $0.648 \pm 0.006$ & $0.644 \pm 0.006$ \\
2.35 & $0.799 \pm 0.008$ & $0.792 \pm 0.008$ \\
1.00 & -- & $0.942 \pm 0.011$ \\
& & \\
SIab 1.09 & $-\cdots$ & $1.387 \pm 0.019$ \\
0.50 & $-\cdots$ & $2.056 \pm 0.035$ \\
0.16 & $4.656 \pm 0.047$ & $4.690 \pm 0.070$ \\
\hline
\end{tabular}


TABLE 3. SUMMARY OF INTRA-CELL STRUCTURE MEASUREMENTS FOR TRX AND SLAB LATTICES

\begin{tabular}{|c|c|c|c|c|c|}
\hline \multirow[b]{3}{*}{$\begin{array}{l}\text { Fast } \\
\text { advantage } \\
\text { factors: }\end{array}$} & \multicolumn{2}{|c|}{ TRX } & \multicolumn{3}{|c|}{ Slabs } \\
\hline & $8.1 / 1$ & $1 / 1$ & $1.09 / 1$ & $0.5 / 1$ & $0.16 / 1$ \\
\hline & & & & & \\
\hline$U^{238}(n, f)$ & $1.431 \pm 0.005$ & $1.073 \pm 0.006$ & $1.256 \pm 0.007$ & $1.113 \pm 0.005$ & $1.041 \pm 0.006$ \\
\hline $\mathrm{AI}^{27}(\mathrm{n}, \alpha)$ & --- & --- & $1.214 \pm 0.01$ & $1.112 \pm 0.005$ & $1.030 \pm 0.007$ \\
\hline$N i^{58}(n, p)$ & -- & --- & $1.274 \pm 0.02$ & $1.1 .14 \pm 0.010$ & $1.052 \pm 0.01$ \\
\hline $\begin{array}{l}\text { Resonance } \\
\text { disadvantage } \\
\text { factors: }\end{array}$ & & & & & \\
\hline $\mathrm{Au}^{197}(\mathrm{n}, \gamma)$ & $1.059 \pm 0.007$ & $1.045 \pm 0.009$ & $1.24 \pm 0.01$ & $1.21 \pm 0.02$ & $1.15 \pm 0.01$ \\
\hline $\operatorname{In}^{115}(\mathrm{n}, \gamma)$ & $1.006 \pm 0.005$ & $1.039 \pm 0.006$ & $1.09 \pm 0.01$ & $1.04 \pm 0.02$ & $1.02 \pm 0.02$ \\
\hline
\end{tabular}

TABLE 4. CONTRIBUTIONS TO THE DILUTE U ${ }^{238}$ RESONANCE INTEGRAL

\begin{tabular}{|c|c|}
\hline Reson & $\begin{array}{l}\text { nce Integral, } \\
\text { barns }\end{array}$ \\
\hline \multicolumn{2}{|l|}{ Smooth capture: } \\
\hline $24,800 \mathrm{ev}$ to $10 \mathrm{Mev}$ & 0.95 \\
\hline \multicolumn{2}{|l|}{ P-wave smooth capture: } \\
\hline Below 24,800 ev & 1.00 \\
\hline \multicolumn{2}{|l|}{ Resolved S-wave resonances: } \\
\hline $0.625 \mathrm{ev}$ to $2030 \mathrm{ev}$ & 267.17 \\
\hline \multicolumn{2}{|l|}{ Unresolved S-wave resonances: } \\
\hline $2030 \mathrm{ev}$ to $24,800 \mathrm{ev}$ & 1.24 \\
\hline \multicolumn{2}{|l|}{ Negative energy resonance: } \\
\hline Above $0.625 \mathrm{ev}$ (smooth capture) & 0.08 \\
\hline Total & 270.44 \\
\hline
\end{tabular}


TABLE 5. EFFECTIVE RESONANCE INTEGRALS FOR ISOLATED URANIUM AND UO 2 RODS CALCULATED BY RESQ-ZUT-TUZ

\begin{tabular}{|c|c|c|c|c|c|c|}
\hline \multirow{2}{*}{\multicolumn{2}{|c|}{$\begin{array}{c}\sqrt{\mathrm{S} / \mathrm{M}} \\
(\mathrm{cm} \mathrm{gm}-1 / 2) \\
\end{array}$}} & \multirow[b]{2}{*}{$\begin{array}{c}\text { Radius, } \\
\mathrm{cm}\end{array}$} & \multicolumn{4}{|c|}{ Iodine, barns } \\
\hline & & & $\begin{array}{c}\text { RESQ } \\
1 \text { to } 200 \mathrm{eV} \\
\end{array}$ & 200 to $2030 \mathrm{ev}$ & 2030 to $24,800 \mathrm{ev}$ & $\begin{array}{c}\text { Total* } \\
0.5 \text { ev to } 10 \mathrm{Mev} \\
\end{array}$ \\
\hline \multirow{4}{*}{ Mets } & 0.556 & 0.3430 & $12.764 \pm 0.065$ & 2.180 & 0.786 & $18.20 \pm 0.07$ \\
\hline & 0.464 & 0.4915 & $10.769 \pm 0.079$ & 1.890 & 0.727 & $15.86 \pm 0.08$ \\
\hline & 0.373 & 0.7620 & $8.707 \pm 0.078$ & 1.599 & 0.662 & $13.44 \pm 0.08$ \\
\hline & 0.259 & 1.588 & $6.252 \pm 0.211$ & 1.268 & 0.578 & $10.57 \pm 0.11$ \\
\hline \multirow{4}{*}{$\mathrm{UO}_{2}$} & 0.734 & 0.3534 & $18.371 \pm 0.087$ & 3.005 & 0.927 & $24.77 \pm 0.09$ \\
\hline & 0.623 & 0.4908 & $15.840 \pm 0.063$ & 2.647 & 0.877 & $21.83 \pm 0.06$ \\
\hline & 0.520 & 0.7044 & $13.382 \pm 0.091$ & 2.324 & 0.824 & $19.00 \pm 0.09$ \\
\hline & 0.414 & 1.111 & $11.374 \pm 0.059$ & 2.006 & 0.764 & $16.61 \pm 0.06$ \\
\hline
\end{tabular}

*This includes the following smooth capture integral:

24,800 ev to $10 \mathrm{Mev}$

0.95 barn

P-wave below $24,800 \mathrm{ev}$

1.00 barn

$0.5 \mathrm{ev}$ to $1.0 \mathrm{ev}$ and resonance tails not in RESQ

$$
\frac{0.52 \text { barn }}{2.47 \text { barns }}
$$


TABLE 6. EFFECTIVE RESONANCE INTEGRALS IN URAIIIUM METAL LATTICES CALCULATED BY RESQ-ZUT-TUZ AND BY RECAP†

\begin{tabular}{|c|c|c|c|c|c|c|}
\hline \multirow{2}{*}{\multicolumn{2}{|c|}{ Lattice }} & \multirow[b]{2}{*}{$(1-C)$} & \multirow{2}{*}{$\begin{array}{c}\sqrt{(\mathrm{S} / \mathrm{M})^{*}} \\
\left(\mathrm{~cm} \mathrm{gm}^{-1 / 2}\right) \\
\end{array}$} & \multicolumn{2}{|c|}{ Resonance Integral, barns } & \multirow[b]{2}{*}{$\frac{\mathrm{RECAP}}{\mathrm{R}-\mathrm{Z}-\mathrm{T}}$} \\
\hline & & & & $\begin{array}{c}\text { RESQ-ZUT-TUZ } \\
(0.5 \mathrm{ev} \text { to } 10 \mathrm{Mev})\end{array}$ & $\begin{array}{c}\text { RECAP } \\
(0.5 \mathrm{ev} \text { to } 10 \mathrm{Mev})\end{array}$ & \\
\hline & 1.00 & $0.6238 \pm 0.0040$ & 0.369 & $13.16 \pm 0.12$ & $13.34 \pm 0.07$ & $1.014 \pm 0.011$ \\
\hline & 2.35 & $0.8568 \pm 0.0017$ & 0.430 & $14.94 \pm 0.10$ & $15.12 \pm 0.07$ & $1.012 \pm 0.009$ \\
\hline & 4.02 & $0.9389 \pm 0.0013$ & 0.450 & $15.38 \pm 0.06$ & $15.71 \pm 0.15$ & $1.021 \pm 0.012$ \\
\hline & 8.11 & $0.9858 \pm 0.0008$ & 0.461 & $15.79 \pm 0.08$ & $15.97 \pm 0.21$ & $1.011 \pm 0.016$ \\
\hline \multirow[t]{3}{*}{ Slab } & 1.09 & $0.9951 \neq$ & 0.205 & -- & $9.09 \pm 0.06$ & -- \\
\hline & 0.50 & 0.9304 & 0.198 & -- & $8.89 \pm 0.03$ & -- \\
\hline & 0.16 & 0.6195 & 0.162 & -- & $7.80 \pm 0.03$ & --- \\
\hline
\end{tabular}

$(S / M) *=(S / M)(1-C)$

tSame cross sections used in both calculations. There is 1.0 barn of P-wave capture below $24,800 \mathrm{ev}$. \#For slab lattices I-C obtained from Placzek escape probabilities. 


\begin{tabular}{|c|c|c|c|c|c|c|c|c|c|}
\hline \multirow{2}{*}{\multicolumn{2}{|c|}{ Rate }} & \multicolumn{2}{|c|}{$\mathrm{TRX} W / \mathrm{U}=8.11$} & \multicolumn{2}{|c|}{ TRX W/U $=4.02$} & \multicolumn{2}{|c|}{$T R X W / U=2.35$} & \multicolumn{2}{|c|}{$\mathrm{TRX} W / \mathrm{U}=1.00$} \\
\hline & & $\overline{R E C A P}$ & Leakage & RECAP & Leakage & RECAP & Leakage & $\overline{R E C A P}$ & Leakage \\
\hline $\mathrm{U}^{238}$ & fission & $0.01856(1.0 \%)$ & 0.97823 & $0.02808 \quad(0.8 \%)$ & 0.89826 & $0.03823 \quad(0.7 \%)$ & 0.90341 & $0.05570 \quad(0.3 \%)$ & 1.0204 \\
\hline$\nu$ & fission & $0.05206(1.0 \%)$ & 0.97823 & $0.07860 \quad(0.8 \%)$ & 0.89826 & $0.10693(0.7 \%)$ & 0.90341 & $0.15554 \quad(0.3 \%)$ & 1.0204 \\
\hline & capture & $0.06929(1.0 \%)$ & 0.98554 & $0.12821 \quad(1.2 \%)$ & 0.88141 & $0.19546 \quad(1.2 \%)$ & 0.87217 & $0.33940 \quad(0.6 \%)$ & 0.95282 \\
\hline$U^{235}$ & fission & $0.01371(1.5 \%)$ & 0.98433 & $0.02494 \quad(1.0 \%)$ & 0.87579 & $0.03892 \quad(0.7 \%)$ & 0.86517 & $0.07072 \quad(0.7 \%)$ & 0.93891 \\
\hline$\nu$ & fission & $0.03355(1.5 \%)$ & 0.98433 & $0.06100 \quad(1.0 \%)$ & 0.87579 & $0.09520 \quad(0.7 \%)$ & 0.86517 & $0.17296 \quad(0.7 \%)$ & 0.93891 \\
\hline & capture & $0.00623(3.0 \%)$ & 0.98418 & $0.01158 \quad(1.4 \%)$ & 0.87583 & $0.01809 \quad(1.0 \%)$ & 0.86339 & $0.03278 \quad(0.9 \%)$ & 0.93727 \\
\hline$Q(0.6$ & $25 \mathrm{ev})$ & $0.88476(0.1 \%)$ & 0.98584 & $0.80066(0.16 \%)$ & 0.86549 & $0.70425(0.15 \%)$ & 0.85175 & $0.49773(0.32 \%)$ & 0.91425 \\
\hline$u^{238}$ & capture & $0.14244(0.4 \%)$ & 0.98516 & $0.15684(0.18 \%)$ & 0.85300 & $0.15086(0.18 \%)$ & 0.84008 & $0.1 .1591(0.35 \%)$ & 0.91508 \\
\hline $\mathrm{U}^{235}$ & fission & 0.38370 & & 0.42032 & & 0.40102 & & 0.30102 & \\
\hline & fission & 0.93239 & & 1.02138 & & 0.97448 & & 0.73148 & \\
\hline & capture & 0.06469 & 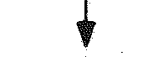 & 0.07120 & + & 0.06836 & $\downarrow$ & 0.05201 & 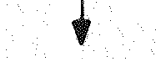 \\
\hline
\end{tabular}

*Major reaction rates in the cell above and below $0.625 \mathrm{ev}, \mathrm{Q}(0.625 \mathrm{ev})$ is the slowing down rate across 0.625 ev. Normalization is to one neutron born of fission. 
TABLE 8. RECAP RESULTS AND LEAKAGE CORRECTION FACTORS FOR NATURAL SLAB LATTICES*

\begin{tabular}{|c|c|c|c|c|c|c|}
\hline \multirow[b]{2}{*}{ Rate } & \multicolumn{2}{|c|}{$\mathrm{W} / \mathrm{U}=1.09$} & \multicolumn{2}{|c|}{$\mathrm{W} / \mathrm{U}=0.50$} & \multicolumn{2}{|c|}{$\mathrm{W} / \mathrm{U}=0.16$} \\
\hline & RECAP & Leakage & RECAP & Leakage & RECAP & Leakage \\
\hline$U^{238}$ fission & $0.06179(0.9 \%)$ & 1.0206 & $0.07453(0.9 \%)$ & 1.0612 & $0.09077(0.3 \%)$ & 1.2258 \\
\hline$v$ fission & $0.17284 \quad(0.9 \%)$ & 1.0206 & $0.20818(0.9 \%)$ & 1.0612 & $0.25311(0.3 \%)$ & 1.2258 \\
\hline capture & $0.24919(0.7 \%)$ & 1.0331 & $0.42404(0.4 \%)$ & 1.1278 & $0.68065(0.2 \%)$ & 1.6266 \\
\hline$U^{235}$ fission & $0.03642(1.0 \%)$ & 1.0367 & $0.05948(0.3 \%)$ & 1.1451 & $0.08231 \quad(0.5 \%)$ & 1.7240 \\
\hline$v$ fission & $0.08915(1.0 \%)$ & 1.0367 & $0.14540(0.3 \%)$ & 1.1457 & $0.20103(0.5 \%)$ & 1.7240 \\
\hline capture & $0.01584 \quad(1.6 \%)$ & 1.0381 & $0.02601(0.8 \%)$ & 1.1496 & $0.03465(1.0 \%)$ & 1.7607 \\
\hline$Q(0.625 \mathrm{ev})$ & $0.63450(0.3 \%)$ & 1.0412 & $0.41583(0.3 \%)$ & 1.1688 & $0.11571(0.8 \%)$ & 1.8993 \\
\hline$U^{238}$ capture & $0.19939(0.3 \%)$ & 1.0456 & $0.14779(0.3 \%)$ & 1.1792 & $0.04431 \quad(0.8 \%)$ & 1.9594 \\
\hline$U^{235}$ fission & 0.28261 & & 0.20599 & & 0.05894 & \\
\hline$v$ fission & 0.68674 & & 0.50056 & & 0.14322 & \\
\hline capture & 0.04816 & 1 & 0.03564 & 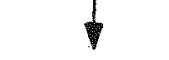 & 0.01051 & $\downarrow$ \\
\hline
\end{tabular}

*Major reaction rates in the cell above and below $0.625 \mathrm{ev} . Q(0.625 \mathrm{ev})$ is the slowing down rate across $0.625 \mathrm{ev}$. Normalization is to one neutron born of fission. 
TABLE 9. COMPARISON OF CALCULATED U 238 FISSION RATES AND FAST ADVANTAGE FACTORS

\begin{tabular}{|c|c|c|c|c|}
\hline \multirow[b]{2}{*}{ Lattice } & \multicolumn{2}{|c|}{$\mathrm{U}^{238}$ Fission } & \multicolumn{2}{|c|}{$\mathrm{U}^{238}$ Fast Advantage Factor } \\
\hline & MOCA & RECAP & MOCA & RECAP \\
\hline TRX 8.11 & $0.0188(1.0 \%)$ & $0.0186(1.0 \%)$ & $1.440(1.0 \%)$ & $1.442(1.5 \%)$ \\
\hline 4.02 & 0.0280 & $0.0281 \quad(0.8 \%)$ & 1.214 & $1.231(1.3 \%)$ \\
\hline 2.35 & 0.0380 & $0.0382(0.7 \%)$ & 1.131 & $1.146(1.3 \%)$ \\
\hline 1.00 & 0.0565 & $0.0557(0.3 \%)$ & 1.065 & $1.054(0.9 \%)$ \\
\hline Slab 1.09 & 0.0622 & $0.0618 \quad(0.9 \%)$ & 1.310 & $1.325(2.4 \%)$ \\
\hline 0.50 & 0.0762 & $0.0745(0.9 \%)$ & 1.155 & $1.170(1.9 \%)$ \\
\hline 0.16 & --- & $0.0908(0.3 \%)$ & -- & $1.066(0.9 \%)$ \\
\hline
\end{tabular}

TABLE 10. COMPARISON OF CALCUIATED AND MEASURED $\rho^{28}(0.625 \mathrm{ev})$

\begin{tabular}{|r|c|c|c|c|}
\hline Lattice & $\begin{array}{c}\text { Leakage } \\
\text { Factor }\end{array}$ & $\rho^{28}(0.625 \mathrm{ev})$ & $\rho^{28}(0.625 \mathrm{ev})$ & Calculated/Measured \\
\hline $\mathrm{TRX} 8.11$ & 1.000 & $0.487 \pm 0.005$ & $0.466 \pm 0.010$ & $1.045 \pm 0.023$ \\
4.02 & 1.033 & $0.845 \pm 0.010$ & $0.830 \pm 0.015$ & $1.018 \pm 0.022$ \\
2.35 & 1.038 & $1.345 \pm 0.016$ & $1.311 \pm 0.020$ & $1.026 \pm 0.019$ \\
1.00 & 1.039 & $3.05 \pm 0.021$ & $3.01 \pm 0.05$ & $1.013 \pm 0.018$ \\
$\mathrm{SIab} 1.09$ & 0.988 & $1.235 \pm 0.010$ & $1.21 \pm 0.03$ & $1.021 \pm 0.026$ \\
0.50 & 0.956 & $2.74 \pm 0.02$ & $2.63 \pm 0.06$ & $1.042 \pm 0.024$ \\
0.16 & 0.830 & $12.8 \pm 0.2$ & $12.1 \pm 0.2$ & $1.058 \pm 0.023$ \\
\hline
\end{tabular}


TABLE 11. COMPARISON OF CALCULATED AND MEASURED $\delta^{25}(0.625 \mathrm{ev})$

\begin{tabular}{|c|c|c|c|c|}
\hline Lattice & $\begin{array}{c}\text { Leakage } \\
\text { Correction } \\
\text { Factor }\end{array}$ & $\begin{array}{c}\text { Calculated } \\
\delta^{25}(0.625 \mathrm{ev})\end{array}$ & $\begin{array}{c}\text { Measured } \\
\delta^{25}(0.625 \mathrm{ev})\end{array}$ & Calculated/Measured \\
\hline TRX 8.11 & 0.999 & $0.0357 \pm 0.0006$ & $0.0352 \pm 0.0004$ & $1.014 \pm 0.020$ \\
4.02 & 1.027 & $0.0609 \pm 0.0006$ & $0.0608 \pm 0.0007$ & $1.002 \pm 0.016$ \\
2.35 & 1.030 & $0.0999 \pm 0.0010$ & $0.0981 \pm 0.001$ & $1.018 \pm 0.014$ \\
1.00 & 1.026 & $0.241 \pm 0.002$ & $0.230 \pm 0.003$ & $1.048 \pm 0.015$ \\
Slab 1.09 & 0.992 & $0.128 \pm 0.001$ & $0.124 \pm 0.002$ & $1.032 \pm 0.018$ \\
0.50 & 0.971 & $0.280 \pm 0.002$ & $0.267 \pm 0.006$ & $1.049 \pm 0.023$ \\
0.16 & 0.880 & $1.23 \pm 0.02$ & $1.10 \pm 0.02 *$ & $1.118 \pm 0.024$ \\
\hline
\end{tabular}

*Average of $1.117 \pm 0.02$ (integral measurement) and $1.081 \pm 0.02$ (differential measurement).

TABLE 12. COMPARISON OF CALCULATED AND MEASURED $\delta^{28}$

\begin{tabular}{|c|c|c|c|c|}
\hline Lattice & $\begin{array}{c}\text { Leakage } \\
\text { Factor }\end{array}$ & $\begin{array}{c}\text { Calculated } \\
\delta^{28}\end{array}$ & $\begin{array}{c}\text { Measured } \\
\text { 28 }\end{array}$ & Calculated/Measured \\
\hline TRX 8.1.1 & 0.993 & $0.0464 \pm 0.0005$ & $0.0452 \pm 0.0007$ & $1.027 \pm 0.019$ \\
4.02 & 1.051 & $0.0663 \pm 0.0005$ & $0.0667 \pm 0.0020$ & $0.994 \pm 0.031$ \\
2.35 & 1.073 & $0.0932 \pm 0.0007$ & $0.0914 \pm 0.0020$ & $1.020 \pm 0.023$ \\
1.00 & 1.102 & $0.166 \pm 0.001$ & $0.163 \pm 0.004$ & $1.018 \pm 0.026$ \\
Slab 1.09 & 0.977 & $0.189 \pm 0.002$ & $0.190 \pm 0.004$ & $0.995 \pm 0.024$ \\
0.50 & 0.906 & $0.254 \pm 0.004$ & $0.264 \pm 0.006$ & $0.962 \pm 0.028$ \\
0.16 & 0.673 & $0.432 \pm 0.013$ & $0.442 \pm 0.009$ & $0.977 \pm 0.036$ \\
\hline
\end{tabular}


TABLE 13. CALCULATED EIGENVALUES

\begin{tabular}{|c|c|c|}
\hline Lattice & $\begin{array}{c}\text { Leakage } \\
\text { Correction } \\
\text { Factor }\end{array}$ & $\begin{array}{c}\text { Calculated } \\
\text { Eigenvalue }\end{array}$ \\
\hline $\operatorname{TRX} 8.11$ & 0.9848 & $1.0025 \pm 0.005$ \\
4.02 & 0.8573 & $0.9953 \pm 0.004$ \\
2.35 & 0.8479 & $0.9976 \pm 0.004$ \\
1.00 & 0.9344 & $0.9905 \pm 0.004$ \\
$\mathrm{Slab} 1.09$ & 1.0403 & $0.987 \pm 0.009$ \\
0.50 & 1.1450 & $0.978 \pm 0.018$ \\
0.16 & 1.569 & $0.938 \pm 0.036$ \\
\hline
\end{tabular}

TABLE 14. COMPARISON OF MEASURED AND CALCULATED FAST/EPITHERMAL SPECTRUM RESULTS: TRX $1.00 / 1$ RELATIVE TO TRX $8.11 / 1$

\begin{tabular}{|c|c|c|c|}
\hline \multirow{2}{*}{ Detector } & \multicolumn{2}{|c|}{ Relative Activation* } & \multirow{2}{*}{ Calculation/Experiment } \\
\cline { 2 - 4 } & Experiment & Calculation & $1.023 \pm 0.030$ \\
$\mathrm{U}^{238}(\mathrm{n}, \mathrm{f})$, fuel & $0.710 \pm 0.007$ & $0.726 \pm 0.007$ & $0.998 \pm 0.034$ \\
$\mathrm{Au}^{197}(\mathrm{n}, \gamma), \mathrm{H}_{2} \mathrm{O}$ & $0.962 \pm 0.008$ & $0.960 \pm 0.020$ & 1.000 \\
$\mathrm{In}^{115}(\mathrm{n}, \gamma), \mathrm{H}_{2} \mathrm{O}$ & $1.00 \pm 0.006$ & $1.00 \pm 0.026$ & $1.000 \pm 0.031$ \\
$\mathrm{U}^{238}(\mathrm{n}, \gamma)$, fuel & $1.104 \pm 0.011$ & $1.103 \pm 0.013$ & 1.000 \\
\hline
\end{tabular}

* Activation in TRX $1.00 / 1$ relative to that in TRX $8.11 / 1$, normalized to unity for $\operatorname{In} 115(n, \gamma)$. 
TABLE 15. COMPARISON OF MEASURED AND CALCULATED FAST/EPITHERMAL SPECTRUM RESULTS: $0.50 / 1$ AND $0.16 / 1$ SLABS RELATIVE TO $1.09 / 1$ SLAB*

\begin{tabular}{|c|c|c|c|c|c|c|}
\hline \multirow[b]{2}{*}{ Detector } & \multicolumn{3}{|c|}{$0.50 / 1$} & \multicolumn{3}{|c|}{$0.16 / 1$ Slab } \\
\hline & Experiment & Calculation & $\mathrm{Calc} / \mathrm{Exp}$ & Experiment & Calculation & $\mathrm{CaIc/Exp}$ \\
\hline$u^{238}(n, f)$, fuel & $0.832 \pm 0.009$ & $0.774 \pm 0.010$ & $0.930 \pm 0.024$ & $0.803 \pm 0.010$ & $0.778 \pm 0.008$ & $0.969 \pm 0.025$ \\
\hline $\mathrm{Au}^{197}(\mathrm{n}, y), \mathrm{H}_{2} \mathrm{O}$ & $1.022 \pm 0.012$ & $1.010 \pm 0.021$ & $0.988 \pm 0.030$ & $1.019 \pm 0.007$ & $1.029 \pm 0.024$ & $1.010 \pm 0.031$ \\
\hline $\operatorname{In}^{115}(\mathrm{n}, \gamma), \mathrm{H}_{2} \mathrm{O}$ & $1.000 \pm 0.010$ & $1.000 \pm 0.015$ & 1.000 & $1.000 \pm 0.011$ & $1.000 \pm 0.016$ & 1.000 \\
\hline$U^{238}(n, \gamma)$, fuel & $1.166 \pm 0.020$ & $1.159 \pm 0.009$ & $0.994 \pm 0.026$ & $1.863 \pm 0.024$ & $1.895 \pm 0.013$ & $1.017 \pm 0.024$ \\
\hline
\end{tabular}

*Activation relative to that in $1.09 / 1$ slab, normalized to unity for $\operatorname{In}^{115}(\mathrm{n}, y)$. 
TABLE 16. EFFECT OF 0.35-BARN REDUCTION OF U $\mathrm{U}^{238}$ SMOOTH CAPTURE INTEGRAL (Calculation $\mathrm{B}$ )

\begin{tabular}{|r|r|c|c|}
\hline \multirow{2}{*}{ Lattice } & \multicolumn{3}{|c|}{ Modified Calculation/Measurement* } \\
\cline { 2 - 4 } TRX 8.11 & $1.0046 \pm 0.005$ & $1.024 \pm 0.023$ & $1.027 \pm 0.019$ \\
& $\lambda$ & $\rho^{28}(0.625)$ & $\delta^{28}$ \\
4.02 & $0.9980 \pm 0.004$ & $0.995 \pm 0.022$ & $0.994 \pm 0.031$ \\
2.35 & $1.0021 \pm 0.004$ & $1.001 \pm 0.019$ & $1.020 \pm 0.023$ \\
1.00 & $0.9943 \pm 0.004$ & $0.980 \pm 0.018$ & $1.010 \pm 0.026$ \\
Slab 1.09 & $0.995 \pm 0.009$ & $0.983 \pm 0.026$ & $0.985 \pm 0.024$ \\
0.50 & $0.994 \pm 0.018$ & $0.997 \pm 0.024$ & $0.942 \pm 0.028$ \\
0.16 & $0.973 \pm 0.036$ & $0.989 \pm 0.023$ & $0.930 \pm 0.036$ \\
\hline
\end{tabular}

* Other parameters were not significantly affected.

TABLE 17. EFFECT OF DECK $718 B \mathrm{U}^{235}$ EPITHERMAL CROSS SECTIONS (Calculation $\mathrm{C}$ )

\begin{tabular}{|r|c|c|c|}
\hline \multirow{2}{*}{ Lattice } & \multicolumn{3}{|c|}{ Modified Calculation/Measurement* } \\
\cline { 2 - 4 } & $\lambda$ & $\delta^{28}$ & $\delta^{25}$ \\
\hline TRX 8.11 & $1.0047 \pm 0.005$ & $1.027 \pm 0.025$ & $0.974 \pm 0.023$ \\
4.02 & $0.9991 \pm 0.004$ & $1.001 \pm 0.025$ & $1.013 \pm 0.017$ \\
2.35 & $1.0000 \pm 0.004$ & $0.997 \pm 0.025$ & $1.011 \pm 0.014$ \\
1.00 & $0.9902 \pm 0.004$ & $0.992 \pm 0.025$ & $1.030 \pm 0.015$ \\
S1ab 1.09 & $0.985 \pm 0.009$ & $0.979 \pm 0.025$ & $1.037 \pm 0.020$ \\
0.50 & $0.991 \pm 0.018$ & $0.957 \pm 0.025$ & $1.042 \pm 0.024$ \\
0.16 & $0.952 \pm 0.036$ & $0.950 \pm 0.035$ & $1.079 \pm 0.020$ \\
\hline
\end{tabular}

* Other parameters were not significantly affected. 
TABLE 18. EFFECT OF YOM64 INELASTIC SCATTERING FOR U 238 (Calculation D)

\begin{tabular}{|r|c|c|}
\hline \multirow{2}{*}{ Lattice } & \multicolumn{2}{|c|}{ Modified Calculation/Measurement* } \\
\cline { 2 - 3 } TRX 8.11 & $1.0047 \pm 0.005$ & $1.027 \pm 0.025$ \\
4.02 & $0.9944 \pm 0.004$ & $1.015 \pm 0.025$ \\
2.35 & $0.9953 \pm 0.004$ & $1.041 \pm 0.025$ \\
1.00 & $0.9876 \pm 0.004$ & $1.036 \pm 0.025$ \\
& & \\
S1.ab 1.09 & $0.9873 \pm 0.009$ & $1.023 \pm 0.025$ \\
0.50 & $1.0019 \pm 0.018$ & $1.016 \pm 0.025$ \\
0.16 & $1.0152 \pm 0.036$ & $0.992 \pm 0.035$ \\
\hline
\end{tabular}

*other parameters were not significantly affected. 
-

.

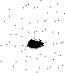

n

$\therefore$

$\therefore$ - 


\section{SUMMARY OF LATTICE PROPERTIES}

\section{A. Fuel}

1. Atomic number

\begin{tabular}{|c|c|c|c|}
\hline Density $\left(x 10^{-24} \mathrm{~cm}^{-3}\right)$ & TRX Metal & TRX $\mathrm{UO}_{2}$ & Natural Slab \\
\hline Fuel: $U^{238}$ & 0.0472050 & 0.0231270 & 0.0474830 \\
\hline$U^{235}$ & 0.0006253 & 0.0003112 & 0.0003401 \\
\hline $0^{16}$ & -- & 0.0469460 & -- \\
\hline Clad: $\quad A_{1} 27$ & 0.0602500 & 0.0602500 & $--\infty$ \\
\hline
\end{tabular}

2. Dimensions, $\mathrm{cm}$

Fuel radius

$0.4915 \quad 0.4864$

Clad inner radius

0.5042

0.5042

Clad outer radius

0.5753

0.5753

Fuel rod length

122

122

Slab thickness
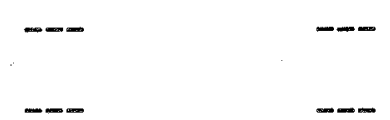

2.5400

Slab length $x$ width

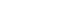

$61 \times 61$

B. $\underline{\mathrm{Cell}}$

1. Atomic number density $\left(\times 10^{-24} \mathrm{~cm}^{-3}\right)$

$$
\begin{array}{lll}
\text { Moderator: } & \mathrm{H}^{1} & 0.06676 \\
& \mathrm{O}^{16} & 0.03338
\end{array}
$$

2. Dimensions

TRX metal

TRX meta.

TRX metal

TRX metal

$\operatorname{TRX} \mathrm{UO}_{2}$
Vol Mod/Vol Fuel

1.00

2.35

4.02

8.11

2.40 $\mathrm{d}_{2} \mathrm{~cm}$

1.4412

1.8060

2.1740

2.8824

1.8060 


$$
\begin{array}{lll}
0.50 & 1.2700 \\
d= & 0.16 & 0.4064 \\
= & \text { moderator thickness, for slab lattices }
\end{array}
$$

The $1.00 / 1$ and $8.11 / 1$ TRX lattices were surrounded by driver regions of $2.40 / 1 \mathrm{TRX} \mathrm{UO}_{2}$.

\section{Lattice Configurations}

\section{$1.00 / 1$ TRX Inner Lattice}

A hexagonel array of 169 rods was removed from the center of the TRX UO, lattice ( $W / F=2.40)$ leaving 1432 rods with an approximately cylindrical outer boundary and a thick water reflector. An inner lattice plate was inserted to center a hexagonal array of 217 TRX metal rods $(W / F=1.00)$ in the resulting space. $B_{\text {axial }}^{2}=0.000526 \mathrm{~cm}^{-2}$.

\subsection{1/1 TRX Inner Lattice}

Every other metal rod of the $1.00 / 1$ TRX inner lattice was removed to leave a hexagonal array of 61 rods with $\mathrm{W} / \mathrm{F}=8.11 .1809 \mathrm{UO}_{2}$ rods were now required in the outer lattice. $\mathrm{B}_{\text {axial }}^{2}=0.000526 \mathrm{~cm}^{-2}$.

\subsection{5/1 TRX Full Lattice}

764 metal rods, fully reflected radially. $B_{a x i a l}^{2}=0.000526 \mathrm{~cm}^{-2}$, $B_{\text {total }}^{2}=0.0057 \pm 0.0001 \mathrm{~cm}^{-2}$.

$4.02 / 1$ TRX FuII Lattice

578 metal rods, fully reflected radially. $B_{a x i a l}^{2}=0.000526 \mathrm{~cm}^{-2}$, $B_{\text {total }}^{2}=0.005469 \pm 0.000036 \mathrm{~cm}^{-2}$.

Natural Slab Cores

The $1.09 / 1$ and $0.5 / 1$ natural slab cores contained 11 fuel slabs, with a highly enriched driver region at each end. Each driver consisted of 20 aluminum fuel boxes arranged in two rows of 10 boxes each, with an aluminum control rod scabbard between the rows. The highly enriched uranium fuel was in the form of 
6.3 w/o U-Zr plates. This type of driver was depicted in the dry lattice experiment report (Reference 2). The measured bucklings, applicable in the asymptotic regions were:

$$
\begin{aligned}
& \mathrm{W} / \mathrm{U}=1.09 \mathrm{~B}_{\text {trans }}^{2}=+0.00367 \pm 0.00006 \mathrm{~cm}^{-2}, \mathrm{~B}_{\text {total }}^{2}=-0.0013 \pm 0.0001 \mathrm{~cm}^{-2} \\
& \mathrm{~W} / \mathrm{U}=0.5 \mathrm{~B}_{\text {trans }}^{2}=+0.00367 \pm 0.00006 \mathrm{~cm}^{-2}, \mathrm{~B}_{\text {total }}^{2}=-0.0037 \pm 0.0003 \mathrm{~cm}^{-2} \\
& \left(\mathrm{~B}_{\text {trans }}^{2} \text { refers to directions parallel to slab faces. }\right)
\end{aligned}
$$

The $0.16 / 1$ core contained 12 fuel slabs between the drivers. There was no asymptotic region in this case. 
-

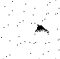

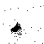

- 
CORRECTION OF $U^{238}$ CAPTURE MEASUREMENTS FOR U 238 FISSION BACKGROUND

Figure B-I shows, as a function of time after irradiation, the activity of a typical cadmium covered $U^{238}$ foil (including fission background) relative to that of a foil with only capture activity, the latter obtained by irradiation in a very thermalized spectrum. The ratio has been normalized to unity at 100 hours.

At first, the time dependence is due to the more rapid decay of the fission activity, while at long times, the situation reverses and the long-lived fission products produce the only persisting activity.

From the amount of the initial rise and the time-dependence of the observed fission activity, one can predict the asymptotic fraction of fission activity. The major uncertainty is the time-dependence of fission activity from about 4 to 100 hours. Two such time variations were used initially, that of Perkins and King (Reference 34) for the gamma activity between 100 and $400 \mathrm{kev}$ from $\mathrm{U}^{235}$ fission products, and also a simple $t^{-1.2}$ variation. Some recent observations by Bunney and Sam (Reference 35) for $U^{238}$ show reasonable agreement with these

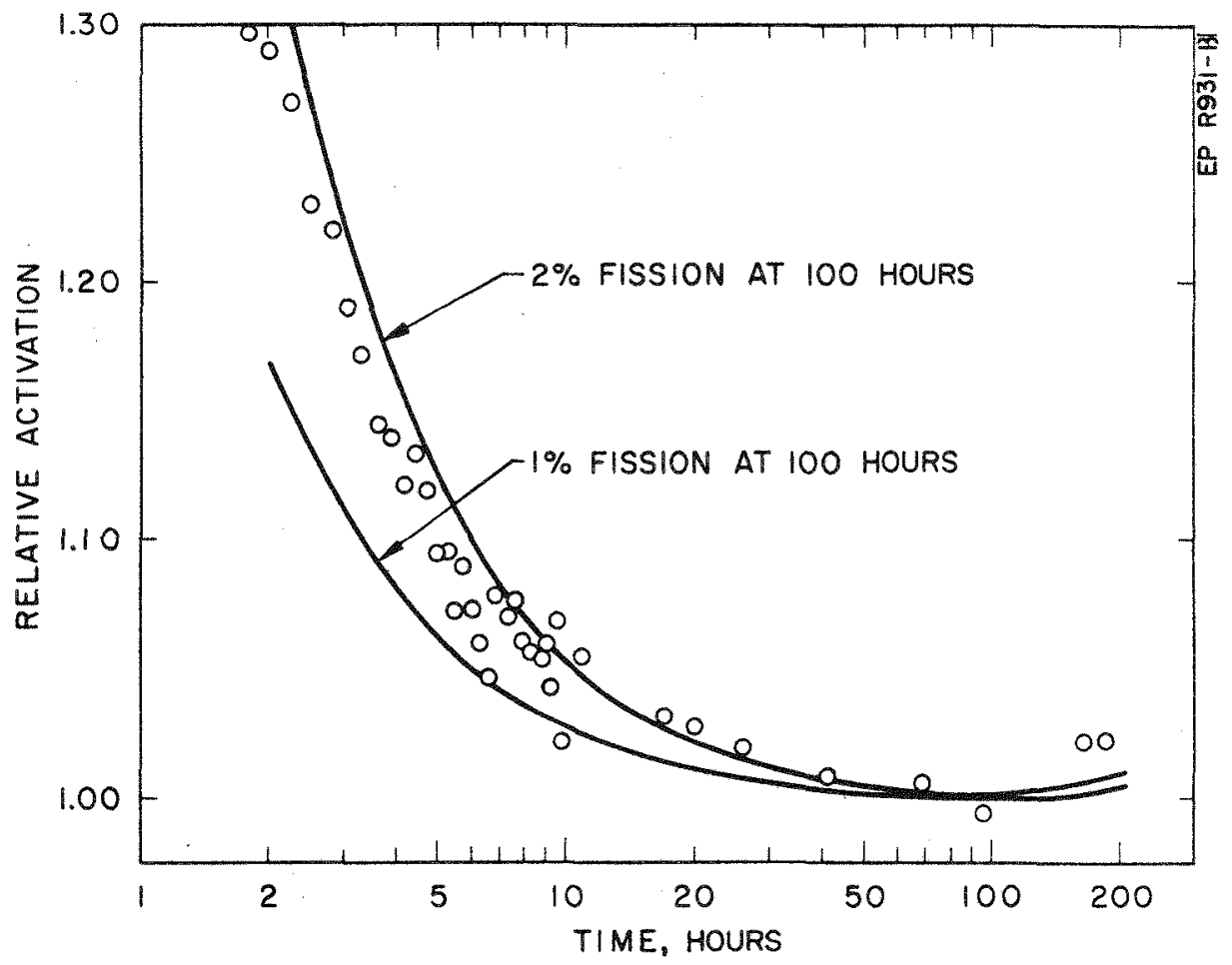

Figure B-I. Epicadium Capture-Plus-Fission Activity Relative to Activity of Foil with Capture Only, TRX $W / U=8.1 / 1$. 
variations between 4 and 72 hours. The corrections range from 1.0 to 3.0 percent. An uncertainty of half the corrections has been applied due entirely to uncertainty of the fission product activity time dependence.

As a check on this method, results were compared with some older unpublished measurements of $\rho^{28}$ for TRX UO $\mathrm{T}_{2}$ lattices. In these, $\rho^{28}$ was determined directiy by counting foil activity; the foils were then dissolved and the capture and fission activities chemically separated by a tracer technique with $\mathbb{N p}^{237}$ (Reference 36). The average ratio of $\rho$ (foils)/ (chemistry) was $1.018 \pm 0.015$ from nine measurements. This lends some support to the correction inferred here from the time dependence. 


\section{REFERENCES}

1. J. J. Volpe, J. Hardy, Jr., and D. Klein, "A Comparison of Thermal Neutron Activation Measurements and Monte Carlo Calculations in Light-Water-Moderated Uranium Cells," WAPD-TM-932, March 1970.

2. D. Klein, A. Z. Kranz, G. G. Smith, W. Baer, and J. DeJuren, "Measurements of Thermal Utilization, Resonance Escape Probability, and Fast Effect in WaterModerated, Slightly Enriched Uranium and Uranium Oxide Lattices," Nucl. Sci. Eng. 3, 403-427 (1958).

3. W. Baer, J. Hardy, Jr., D. Klein; J. J. Volpe, B. L. Palowitch, and F. S. Frantz, Jr., "Study of a Slightly Enriched UO 2 Lattice with H:U=0.42Measurement and Analysis," Nucl. Sci. Eng. 23, 361-367 (1965).

4. E. M. Gelbard, H. B. Ondis, and J. Spanier, "MARC - A Multigroup Monte Carlo Program for the Calculation of Capture Probabilities," WAPD-TM-273, May 1962.

5. H. Bohl, Jr., E. M. Gelbard, B. L. Anderson, A. P. Hemphill, and B. P. Peterson, "P3MG-1 - A One-Dimensional Multigroup P-3 Program for the Philco-2000 Computer," WAPD-TM-272, September 1963.

6. W. H. Guilinger, N. D. Cook, and P. A. Gillis, "SPAN-3 - A Shield Design Program for the Philco-2000 Computer," WAPD-TM-235, February 1962.

7. S. S. Glickstein and W. J. Hall, "Effective Cadmium Cutoff Energies for Finite Cylinarical Filters with Finite-Size Detectors," Nucl. Sci. Eng. 32, 264-265 (1968).

8. A. F. Henry, "54-Group Library for P-I Programs," WAPD-TM-224, April 1960.

9. R. A. Dannels and H. C. Honeck, "MOCA2A - A Fast Effect Monte Carlo Code for the IBM 7090," WCAP-2685.

10. J. B. Garg, J. Rainwater, J. S. Petersen, and W. W. Havens, Jr., "Neutron Resonance Spectroscopy. III. Th ${ }^{232}$ and U ${ }^{238}$ " Phys. Rev. 134B, B985-B1009 $(1964)$.

11. J. R. Stehn, M. D. Goldberg, B. A. Magurno, and R. Wiener-Chasman, "Neutron Cross Sections. Volume I. $Z=1$ To 20," BNI-325 (2nd. Ed.) (Supp1. 2) (Vol. I), U. S. Government Printing Office, Washington, D. C., May 1964.

12. W. A. Wittkopf, D. H. Roy, and A. Z. Livolsi, "238 U Neutron Cross-Section Data for the ENDF/B," BAW-316, May 1967. 
13. H.W. Newson, "Strength Functions and Nuclear Size" in "Nuclear Structure Study with Neutrons. Proceedings of the International Conference held in Antwerp, 19-23 July 1965," M. Neve de Mevergnies, P. Van Assche, and J. J. Vervier, Eds., pp. 195-219, North-Holland Publishing Company, Amsterdam, 1966.

14. J. J. Schmidt, "Neutron Cross Sections for Fast Reactor Materials, Part I. Evaluation," KFK-120, February 1966.

15. E. Barnard, A. T. G. Ferguson, W. R. McMurray, and I. J. Van Heerden, "Time-of-Flight Measurements of Neutron Spectra from the Fission of $U^{235}$, $\mathrm{U}^{238}$ and $\mathrm{Pu}{ }^{239}, "$ Nucl. Phys. 71, 228-240 (1965).

16. R. Batchelor, W. B. Gilboy, and J. H. Towle, "Neutron Interactions with $\mathrm{U}^{238}$ and $\mathrm{Th}^{232}$ in the Energy Región $1.6 \mathrm{MeV}$ to $7 \mathrm{MeV}$," Nucl. Phys. 65, $236-256$ (1965).

17. N. Corngold, "Chemical Binding Effects in the Thermalization of Neutrons," Ann. Phys.(N.Y.) 11, 338-358 (1960).

18. H. Bohl, Jr. and A. P. Hemphil1, "MUFT-5 - A Fast Neutron Spectrum Program for the Philco-2000," WAPD-TM-218, February 1961.

19. W. W. Clendenin, D. E. George, and B. S. Hamill, "MAGMA - A Philco-2000 Program for the Calculation of Scattering Kernels, Neutron Spectra and Few-Group Parameters for Thermal Neutrons," WAPD-TM-373, September 1964.

20. J. Hardy, Jr. and D. Klein, "Spatial Variation of the Fast Neutron Flux in Cells of Slightly 235 U-Enriched-Uranium Water-Moderated Lattices," Nucl. Sci. Eng. 26, 462-471 (1966).

21. B. I. Anderson, E. M. Gelbard, and J. Spanier, "RESQ-2: A Combined AnalyticMonte Carlo Calculation of Resonance Absorption Based on Superposition," WAPD-TM-665, June 1967.

22. J. Chernick, "The Theory of Uranium Water Lattices" in "Proceedings of the International Conference on the Peaceful Uses of Atomic Energy, Geneva 1955," Vol. 5, pp. 215-228, United Nations, New York, 1956.

23. S. Yiftah and M. Sieger, "Nuclear Cross Sections for Fast Reactors," IA-980, July 1964. 
24. E. Hellstrand, "Measurement of Resonance Integrals" in "Reactor Physics in the Resonance and Thermal Regions. Volume II. Resonance Absorption. Proceedings of the National Topical Meeting of the American Nuclear Society, San Diego, February 7-9, 1966," A. J. Goodjohn and G. C. Pomraning, Eds., pp. 151-173, The M. I. T. Press, Cambridge, Massachusetts, 1966.

25. K. Jirlow and E. Johannson, "The Resonance Integral of Gold," J. Nucl. Energy: Pt. A 11, 101-107 (1960).

26. J. Hardy, Jr. and B. I. Palowitch, "The Effective Resonance Integral and Doppler Coefficient of Thorium-Oxide Rods," Nucl. Sci. Eng. 29, III-121 (1967).

27. R. I. Hellens, B. R. Sehgal, and H. Mizuta, "A Comparative Analysis of Some Graphite and Water Moderated Reaćtor Lattices" in "The Physics Problems in Thermal Reactor Design. Proceedings of an International Conference at the Institution of Civil Engineers, London SWI, 27-29 June 1967," pp. 27-38, The British Nuclear Energy Society, London SWI, 1967.

28. J. R. Askew, "Some Problems in the Calculation of Resonance Capture in Lattices" in "Reactor Physics in the Resonance and Thermal Regions. Volume II. Resonance Absorption. Proceedings of the National Topical Meeting of the American Nuclear Society, San Diego, February 7-9, 1966," A. J. Goodjohn and G. C. Pomraning, Eds., pp. 395-419, The M. I. T. Press, Cambridge, Massachusetts, 1966.

29. J. G. Tyror, A. Hart, J. E. Beardwood, and J. D. MacDougall, "Resonance Capture Calculations for Gas-Cooled Reactors" in "Reactor Physics in the Resonance and Thermal Regions. Volume II. Resonance Absorption. Proceedings of the National Topical Meeting of the American Nuclear Society, San Diego, February 7-9, 1966," A. J. Goodjohn and G. C. Pomraning, Eds., pp. 371-393, The M. I. T. Press, Cambridge, Massachusetts, 1966.

30. F. J. Fayers and G. H. Kinchin, "Uranium and Plutonium Fuelled Lattices with Graphite and Water Moderation - A Comparison of Experiment and Theory" in "The Physics Problems in Thermal Reactor Design. Proceedings of an International Conference at the Institution of Civil Engineers, London SWI, 27-29 June 1967," pp. 15-26, The British Nuclear Energy Society, London SWI, 1967.

31. M. Asghar, C. M. Chaffey, and M. C. Moxon, "Low-Energy Neutron Resonance Parameters of ${ }^{238} \mathrm{U}, "$ Nucl. Phys. 85, 305-316 (1966). 
32. N. W. Glass, A. D. Schelberg, L. D. Tatro, and J. H. Warren, "U 238 Neutron Capture Results from Bomb Source Neutrons" in "Neutron Cross Sections and Technology. Proceedings of a Conference held in Washington, D. C., March 4-7, 1968," D. T. Goldman, Ed., National Bureau of Standards Special Publication 299, Volume I, pp. 573-587, U. S. Government Printing Office, Washington, D. C., 1968.

33. W. G. Davey, "Selected Fission Cross Sections for ${ }^{232} \mathrm{Th}, 233_{U}, 234_{U}, 235 \mathrm{U}$,

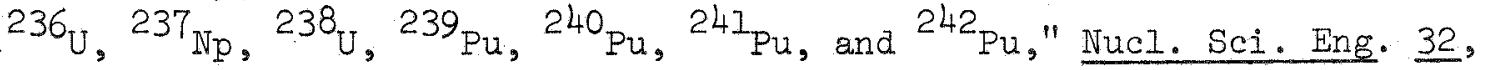
$35-45(1968)$.

34. J. F. Perkins and R. W. King, "Energy Release from the Decay of Fission Products," Nucl. Sei. Eng. 3, 726-746 (1958).

35. I. R. Bunney and D. Sam, "Gamma-Ray Spectra of the Products of Fast-Neutron Fission of ${ }^{235} \mathrm{U}$ and ${ }^{238_{U}}$ at Selected Times After Fission," Nucl. Sci. Eng. 29, $432-443$ (1967).

36. W. Baer, M. J. Galper, and N. Carbone, "Measurements of the Conversion Ratio of the PWR Critical Facility Blanket," Nucl. Sci. Eng. 3, 113-128 (1958). 